\title{
WestVirginiaUniversity
}

THE RESEARCH REPOSITORY @ WVU

Graduate Theses, Dissertations, and Problem Reports

2007

\section{Experimental methodology for measurement of diesel exhaust particulates}

Rakesh Nandivada

West Virginia University

Follow this and additional works at: https://researchrepository.wvu.edu/etd

\section{Recommended Citation}

Nandivada, Rakesh, "Experimental methodology for measurement of diesel exhaust particulates" (2007). Graduate Theses, Dissertations, and Problem Reports. 4323.

https://researchrepository.wvu.edu/etd/4323

This Thesis is protected by copyright and/or related rights. It has been brought to you by the The Research Repository @ WVU with permission from the rights-holder(s). You are free to use this Thesis in any way that is permitted by the copyright and related rights legislation that applies to your use. For other uses you must obtain permission from the rights-holder(s) directly, unless additional rights are indicated by a Creative Commons license in the record and/ or on the work itself. This Thesis has been accepted for inclusion in WVU Graduate Theses, Dissertations, and Problem Reports collection by an authorized administrator of The Research Repository @ WVU. For more information, please contact researchrepository@mail.wvu.edu. 


\title{
Experimental Methodology for Measurement of Diesel Exhaust Particulates
}

\author{
by \\ Rakesh Nandivada \\ Thesis submitted to the \\ College of Engineering and Mineral Resources \\ at West Virginia University \\ in partial fulfillment of the requirements \\ for the degree of \\ Master of Science \\ In \\ Mechanical Engineering
}

Dr. Bruce Kang, Chairperson

Dr. Kenneth H. Means

Dr. Suryanarayana Raju Pakalapati

Department of Mechanical and Aerospace Engineering

Morgantown, West Virginia

2007

Keywords: DEP, TEOM, iServer, Inhalation Chamber, Jet Mill 


\section{ABSTRACT \\ Experimental Methodology for Measurement of Diesel Exhaust Particulates \\ Rakesh Nandivada}

Diesel engine emissions are highly complex mixtures. They consist of a wide range of organic and inorganic compounds distributed among the gaseous and particulate phases. Public health concern has arisen about these emissions for reasons like - the particles in diesel emissions are very small ( $90 \%$ or less than $1 \mu \mathrm{m}$ by size), making them readily respirable, these particles have hundreds of chemicals adsorbed onto their surfaces, including many known or suspected mutagens and carcinogens.

For investigating the effects of Diesel Exhaust Particulates (DEP) on animal samples, a thorough experimental methodology is a must. In this present research a systematic experimental set up has been designed to cater those needs. For that, a well controlled inhalation testing chamber has been demonstrated using i-Server humidity and temperature controller, with which the relative humidity and temperature of the testing chamber can be remotely monitored. For controlling the $\mathrm{RH}$ of the chamber, a voltage switch was connected to the air humidifier. For determining the amount of DEP required for any given inhalation testing chamber, experiments were conducted in Small Animal Inhalation Testing Facility at West Virginia University using NIST 2975 dust. In addition to the experimental results, an analytical model to determine the amount of dust required for any testing chamber has also been derived. The results showed that i-server controller set up, can be successfully used to monitor the testing chamber remotely and the derived model for determining the sample amount is in close agreement with the experimental results. 


\section{ACKNOWLEDGMENTS}

I would like to take this opportunity to thank several people who played a vital role in the successful completion of this thesis. First and foremost, I would like to thank my advisor and committee chairman, Dr. Bruce Kang, for providing his valuable guidance. I thank Dr. Kenneth H. Means for reviewing my thesis and participating on my examination committee. I would like to thank my committee member Dr. Suryanarayana Raju Pakalapati for being very supportive and helpful. Special thanks to Dr. Stanley for his guidance and help during most of my research work.

Also, my special thanks to my friend, Bhyrav Mutnuri, for his help and suggestions. Without him I would not have had the strength to complete this thesis.

Finally, I would like to thank my parents and family members for their love and patience. 


\section{TABLE OF CONTENTS}

ABSTRACT ............................................................................................................................ ii

ACKNOWLEDGMENTS ..................................................................................ii

LIST OF TABLES ......................................................................................................... vi

LIST OF FIGURES .................................................................................................................. vii

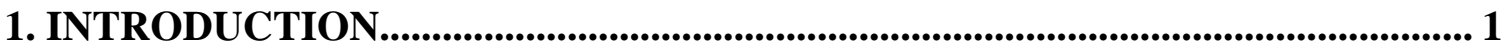

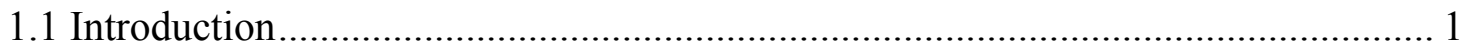

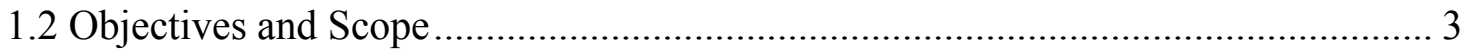

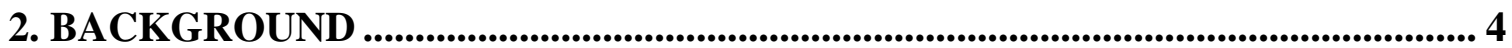

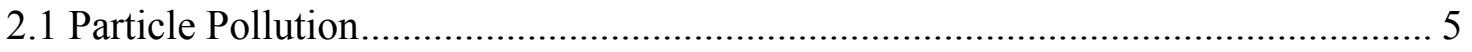

2.1.1 Effects of pollution ................................................................................ 6

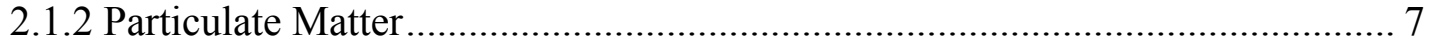

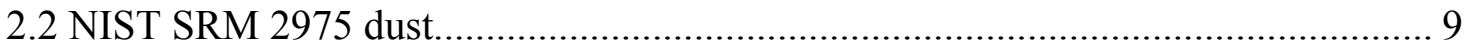

2.2.1 Health effects and Experiments on Rats ...................................................... 9

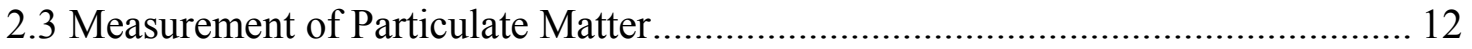

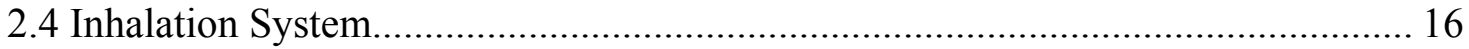

2.4.1 Construction of Inhalation system ………………...................................... 17

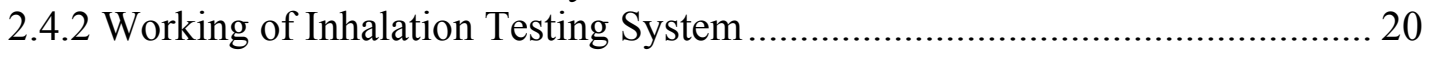

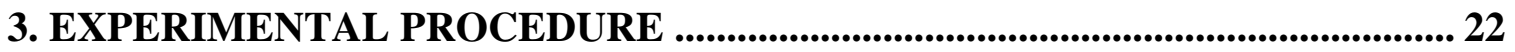

3.1 Monitoring Temperature and Humidity using i-Server ......................................... 22

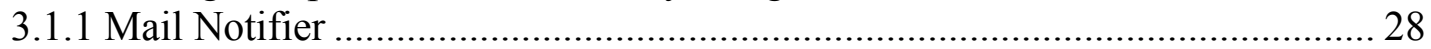

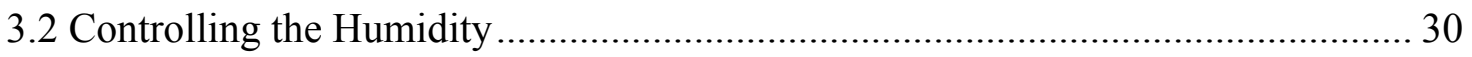

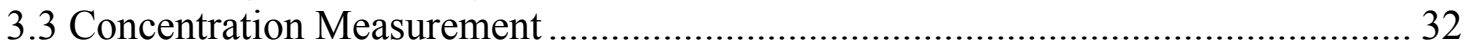

4. EXPERIMENTAL RESULTS AND DISCUSSIONS ............................................. 33

4.1 Monitoring the Relative Humidity and Temperature of the Inhalation Chamber .. 33

4.2 Control of Inhalation Chamber for Relative Humidity and Temperature................ 34

4.3 Measurement of amount of DEP dust required for varying air volume changes and

RH in inhalation chamber ................................................................................... 34

5. THEORETICAL MODELING AND DISCUSSIONS............................................... 46

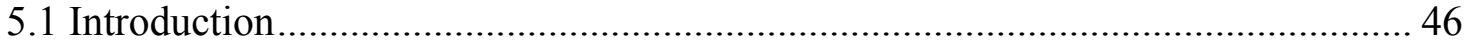

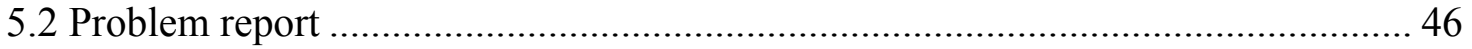

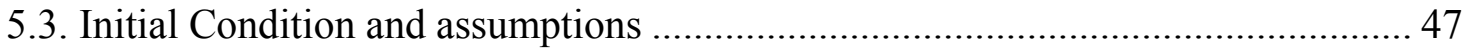

5.4 Comparison between experimental results and theoretical method results ............ 52

5.5 Effect of testing parameters on mass required for experimentation ........................ 54 
6. CONCLUSIONS ....................................................................................................................... 57

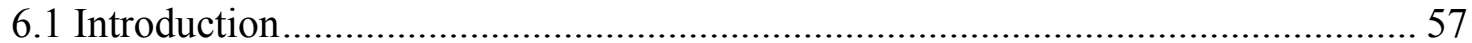

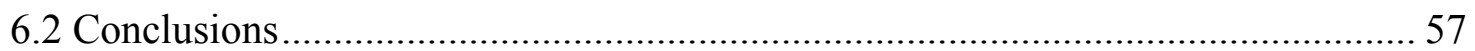

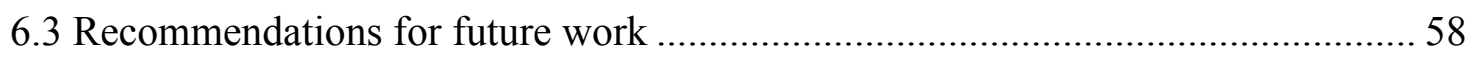

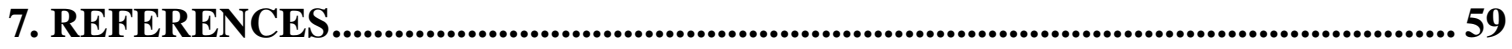

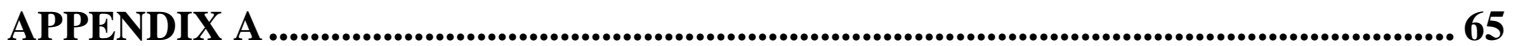

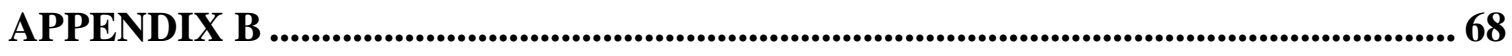

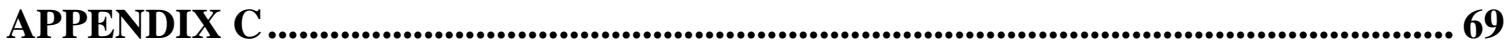




\section{LIST OF TABLES}

Table 1. National Ambient Air Quality Standards...........................................................

Table 2 Specifications of TEOM: (from Thermo Scientific) ........................................15 


\section{LIST OF FIGURES}

Figure 2.1 TEOM Series 1400ab Ambient Particulate Monitor .....................................16

Figure 2.2 Front View of Inhalation System ...........................................................18

Figure 2.3 Side View of Inhalation System Schematic Diagram ..................................19

Figure 2.4 Hazelton Inhalation Exposure Chamber.................................................21

Figure 3.1 iServer on the left and Power supply on the right .....................................23

Figure 3.2 Input/Output Connections of IDRN-PS-1000 Power Supply unit .................24

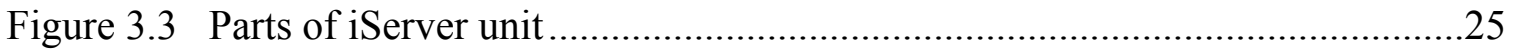

Figure 3.4 Chart displaying Temperature vs. Time and Humidity vs. Time ....................28

Figure 3.5 iServer Mail Notifier Main window ......................................................29

Figure 3.6 Setup and Configuration for Mail Notifier Software .................................30

Figure 4.1 The experiment was started at time 20:44 where 20 represent the hours and 44 represent the minutes. The dust was added to chamber at 20:44. The change in the concentration by TEOM was recognized near 20:47

Figure 4.2 This is the continuation of Figure 4.1 showing from time 20.47 . The vibrator feeder adds the dust continuously and jet mill pumps the dust into the chamber. .39

Figure 4.3 This is the continuation of Figure 4.2 showing from time 20.51. The vibrator feeder adds the dust continuously and jet mill pumps the dust into the chamber .40 
Figure 4.4 This is the continuation of Figure 4.3 showing from time 20.55. As the concentration of dust reaches $20 \mathrm{mg} / \mathrm{m} 3$, the feed rate is adjusted manually to maintain the concentration at $20 \mathrm{mg} / \mathrm{m} 3$

Figure 4.5 This is the continuation of Figure 4.4 showing from time 20.56. The steady concentration of $20 \mathrm{mg} / \mathrm{m} 3$ is maintained for $4 \mathrm{~min}$.

Figure 4.6 This is the continuation of Figure 4.5 showing from time 20.59. As the steady concentration of $20 \mathrm{mg} / \mathrm{m} 3$ was maintained for 4 min (needed for experiment) no dust is added through vibrator feeder and the concentration falls in the chamber as shown after time 21:00

Figure 4.7 This is the continuation of Figure 4.6 showing from time 21.01. This concentration in the chamber is fallen rapidly as no dust is added .42

Figure 4.8 The experiment was started at time 20:36 where 20 represent the hours and 36 represent the minutes. The dust was added to chamber at 20:36. The change in the concentration by TEOM was recognized near 20:38

Figure 4.9 This is the continuation of Figure 4.8 showing from time 20.38 . The vibrator feeder adds the dust continuously and jet mill pumps the dust into the chamber .44

Figure 4.10 This is the continuation of Figure 4.9 showing from time 20.41. The vibrator feeder adds the dust continuously and jet mill pumps the dust into the chamber .45

Figure 4.11 This is the continuation of Figure 4.10 showing from time 20.48. At this point it is close to $20 \mathrm{mg} / \mathrm{m} 3$ and starts to stay near that for some time. .46 
Figure 4.12 This is the continuation of Figure 4.11 showing from time 20.51. As no dust was added further after keeping the concentration close to $20 \mathrm{mg} / \mathrm{m} 3$ the concentration in the chamber falls rapidly. .46

Figure 5.1 Theoretical and experimental values of the amount of DEP consumed for 10 and 4 air cycle changes per hour respectively

Figure 5.2 Chart showing the amount of DEP dust used for 10 and 4 air changes per hour during the experimentation .54

Figure 5.3 Graph representing amount of DEP and transient state time required for different air cycle changes with varying feed rates (Values in Appendix B) ..56 Figure 5.4 Graph representing DEP required for different transient state time periods with varying volume changes per hour (Values in Appendix C) 


\section{INTRODUCTION}

\subsection{Introduction}

In recent years, the health community has focused its attention on the effect of diesel exhaust on health. This is due in part to the increased use of diesels in cars, trucks, and other applications, such as in coal mines and also due to recent attempts to identify additional mechanisms of diesel particulate interaction with the lungs. For example, increased attention is being given to very small particles with diameters below 0.1 micron.

Inhalation exposure to particulate matter in general and diesel exhaust particles (DEP) in particular occurs in the environment and work places. The levels of exposure can vary, but serious health effects have been associated with acute as well as chronic exposures to these particulate matters. Studies have shown that both the gaseous components and the particles themselves play a role in the development of pulmonary diseases. The initial inflammatory injury is linked to other disease states through cell to cell interactions that include respiratory infections, asthma, fibrosis, and tumorgenicity. The effect of DEP on asthma appears to be a particle-derived effect since DEP results in elevated human immune responses to antigen sensitization, suggesting that the organic component of DEP is involved in the suppression of host defenses. Preliminary studies in rats showed that DEP induced pulmonary inflammation and inhibited alveolar macrophage host defense function. 
The purpose of this research is to update the existing whole body Small Animal Inhalation Testing Facility at West Virginia University to investigate the effects of DEP on the development of chronic lung diseases in animal models. The $500 \mathrm{sq} f \mathrm{ft}$ facility was constructed in 1983 as part of a Generic Center established by the U. S. Bureau of Mines. Multidisciplinary projects have been conducted among researchers from Penn State University, West Virginia University, University of Minnesota, and the Hershey Medical Center from 1983 until 1997, when the Bureau of Mines was re-organized. In 1998, the facility received funding from NIOSH to participate in a study of asphalt fume inhalation. The facility will be used as part of a three year study funded by the Nation Heart, Lung, and Blood Institute of the National Institutes of Health, Ma et al., 2003 [1]

Ma et al., (1) showed that diesel exhaust particles (DEP) alter pulmonary immune responses to bacterial infection. Exposure of rats to $100 \mathrm{mg} / \mathrm{m}^{3} \mathrm{DEP}$ for $4 \mathrm{~h}$ was found to aggravate Listeria monocytogenes (Listeria) infection at 3 days postinfection, but the bacteria were largely cleared at 7 days postinfection due to the development of a strong $\mathrm{T}$ cell-mediated immunity. In their study, Ma et al., 2003 [2] examined the effects of repeated DEP exposure at lower doses on pulmonary responses to bacterial infection. Brown Norway rats were exposed to DEP by nose-only inhalation at $20.62 \pm 1.31 \mathrm{mg} / \mathrm{m}^{3}$ for $4 \mathrm{~h} /$ day for 5 days, followed by intratracheal inoculation with 100, 000 Listeria at $2 \mathrm{~h}$ after the last DEP exposure. DEP-exposed rats showed a significant increase in lung bacterial load at both 3 and 7 days postinfection.

The study used nose-only inhalation (the dust was induced into rats using a pipe connected to their nose) which could induce stress in the animals. The goal now is to use 
the whole body inhalation system to validate previous results. In this whole body inhalation system, rats are kept inside the chamber and monitored the affects of dust on their lungs.

\subsection{Objectives and Scope}

These are the main objectives of the present research:

D Updating the inhalation system instrumentation to promote for monitoring temperature and humidity 24 hours per day. This is especially needed for night time safety.

Updating the humidity control instrumentation to automatically control the variations in the humidity in the testing environment through out the process

Estimating the amount (grams) of NIST dust SRM 2975 needed to make the concentration level in the exposure chamber equal to $20 \mathrm{mg} / \mathrm{m}^{3}$ for four hours. The effect of the number of air changes per hour in the chamber is also observed. 


\section{BACKGROUND}

Air quality affects how we live and breathe. It changes from day to day or even hour to hour. The U. S. Environmental Protection Agency (EPA) and others are working to make information about outdoor air quality as easy to understand as the weather forecast. The important tool here is Air Quality Index, or AQI. It is an index for reporting daily air quality. It shows how clean or polluted our air is, and what associated health effects might be of concern.

The Clean Air Act, which was last amended in 1990, requires the EPA to set National Ambient Air Quality Standards for pollutants considered harmful to public health and the environment. The Clean Air Act developed two types of national air quality standards. Primary standards set limits to protect public health, including the health of sensitive populations such as asthmatics, children, and the elderly. Secondary standards set limits to protect public welfare, including protection against decreased visibility, damage to animals, corps, vegetation, and buildings. The EPA Office of Air Quality Planning and Standards (OAQPS) has set National Ambient Air Quality Standards (NAAQS) for six principal pollutants, which are called "criteria" pollutants. They are listed in Table (1). Units of measure for the standards are parts per million (ppm) by volume, milligrams per cubic meter of air $\left(\mathrm{mg} / \mathrm{m}^{3}\right)$, and micrograms per cubic meter of air $\left(\mu \mathrm{g} / \mathrm{m}^{3}\right)$. 
Table 1. National Ambient Air Quality Standards

\begin{tabular}{|c|c|c|c|}
\hline POLLUTANT & $\begin{array}{c}\text { PRIMARY } \\
\text { STANDARDS. }\end{array}$ & AVERAGING TIME & $\begin{array}{l}\text { SECONDARY } \\
\text { STANDARDS }\end{array}$ \\
\hline & $9 \mathrm{ppm}\left(10 \mathrm{mg} / \mathrm{m}^{3}\right)$ & 8-hour & None \\
\hline Monoxide & $\begin{array}{c}35 \mathrm{ppm} \\
\left(40 \mathrm{mg} / \mathrm{m}^{3}\right)\end{array}$ & 1-hour & None \\
\hline Lead & $1.5 \mu \mathrm{g} / \mathrm{m}^{3}$ & Quarterly Average & Same as Primary \\
\hline $\begin{array}{l}\text { Nitrogen } \\
\text { Dioxide }\end{array}$ & $\begin{array}{l}0.053 \mathrm{ppm} \\
\left(100 \mu \mathrm{g} / \mathrm{m}^{3}\right)\end{array}$ & Annual (Arithmetic Mean) & Same as Primary \\
\hline Particulate & $50 \mu \mathrm{g} / \mathrm{m}^{3}$ & Annual (Arith. Mean) & Same as Primary \\
\hline Matter $\left(\mathrm{PM}_{10}\right)$ & $150 \mathrm{ug} / \mathrm{m}^{3}$ & 24-hour & \\
\hline Particulate & $15 \mu \mathrm{g} / \mathrm{m}^{3}$ & Annual (Arith. Mean) & Same as Primary \\
\hline Matter $\left(\mathrm{PM}_{2.5}\right)$ & $65 \mathrm{ug} / \mathrm{m}^{3}$ & 24-hour & \\
\hline \multirow{2}{*}{ Ozone } & $0.08 \mathrm{ppm}$ & 8-hour & Same as Primary \\
\hline & $0.12 \mathrm{ppm}$ & 1-hour & Same as Primary \\
\hline
\end{tabular}

\subsection{Particle Pollution}

Particle pollution is a mixture of microscopic solids and liquid droplets suspended in air. This pollution, also known as particulate matter, is made of a number of components, including acids (such as nitrates and sulfates), organic chemicals, metals, soil or dust particles, and allergens (such as fragments of pollen or mold spores). 
The size of particles is directly linked to their potential for causing health problems. Small particles less than 10 micrometers in diameter pose the greatest problems, because they can get deep into the lungs, and some may even get into the bloodstream. Exposure to such particles can affect both the lungs and the heart. Larger particles are of less concern, although they can irritate eyes, nose, and throat.

Particles less than $2.5 \mu \mathrm{m}$ in diameter are called "fine" particles. These particles are so small they can be detected only with an electron microscope. Sources of theses fine particles includes all types of combustion, including motor vehicles, power plants, residential wood burning, forest fires, agricultural burning, and some industrial processes. Particles between $2.5 \mu \mathrm{m}$ and $10 \mu \mathrm{m}$ in diameter are known as "coarse" particles. These particles are mostly generated by crushing or grinding operations and dust stirred up by vehicles traveling on road.

\subsubsection{Effects of pollution}

Particle exposure can lead to a variety of health effects. Long- and short-term particle exposures have been linked to health problems.

Long-term exposures to particles for many years at high levels have been associated with problems such as reduced lung function and the development of chronic bronchitis, and even premature death.

Short-term exposures to particles (hours or days) can aggravate lung disease, causing asthma attacks and acute bronchitis, and may also increase susceptibility to respiratory infections. In people with heart disease, short-term exposures have been 
linked to heart attacks and arrhythmias. Healthy children and adults have not been reported to suffer serious effects from short-term exposures, although they may experience temporary minor irritation when particle levels are elevated.

\subsubsection{Particulate Matter}

Suspended particulate matter (SPM) are the particles suspended in the air which is constituted of solid and/or low vapor pressure liquid particles that enter the atmosphere from various sources. Particles from different sources would have different size distribution and chemical composition.

One way to characterize particle size is with the aerodynamic diameter. Aerodynamic diameter is defined as the physical diameter of a unit density sphere that settles through the air with a velocity equal to that of the particle in question. It is the most significant aerosol size parameter because it determines the particle's behavior while airborne. Particles exhibiting the same airborne behavior have the same aerodynamic diameter, regardless of their physical size, shape, density, or composition. The aerodynamic particle sizes range from below $0.01 \mu \mathrm{m}$ to $100 \mu \mathrm{m}$ and larger. Instruments used to measure the integral parameters, like the mass, of particles in the air collect particles that fall within a size range, rather than a single size or specific chemical composition. Size is the main determinant of the behavior of an atmospheric particle. The particles depending on physical and chemical processes involved in its formation and growth are divided into different size fractions (also called 'mode') like nucleation, Aitken, accumulation, and coarse modes. 
Nucleation mode lies in the range less than $0.02 \mu \mathrm{m}$ and having maximum number-density of 5-15 $\mathrm{nm}$ particle diameter. Aitken mode particles are in the range of 0.02 to $0.1 \mu \mathrm{m}$ and originate from either primary particles, natural and anthropogenic, or by growth of nucleation mode particles. Little is known about their chemical composition as they constitute a negligible amount in total fine mode mass. Ultrafine particles are in the range less than $0.1 \mu \mathrm{m}$ and they thus include all the particles in nucleation mode and Atkins mode.

The coarse mode particles range below $1 \mu \mathrm{m}$. But by latest convention particles between 2.5 and $10 \mu \mathrm{m}$ are called "coarse particles" and particles less than $2.5 \mu \mathrm{m}$ are called "fine particles".

Particulate Matter PM10 - Aerosol particles that are smaller than or equal to 10 micrometers or have an aerodynamic diameter of 10 micrometers.

Particulate Matter PM2.5 - Aerosol particles that are smaller than or equal to 2.5 micrometers or have an aerodynamic diameter of 2.5 micrometers.

Particulate Matter PM1 - Aerosol particles that are smaller than or equal to 1 micrometers or have an aerodynamic diameter of 1 micrometers.

Total suspended particulates (TSP): They are solid matter or liquid droplets from smoke, dust, fuel ash, or condensing vapors that can be suspended in the air. They either 
come from natural sources such as the sea (wind-blown sea-salt) and soil (wind-blown soil particles) or from man-made sources such as diesel exhausts, construction activities and factories. TSP include a range of different sized particles. The coarser particles are 50-100 micrometers (where 100 micrometers is the thickness of a human hair) and finer particles are smaller than 10 micrometers in diameter.

\subsection{NIST SRM 2975 dust}

Routinely conducted, comprehensive chemical analyses of complex mixtures such as DEPs are not practical and probably not feasible in most laboratories. However, descriptive and analytical data should be available for individual source samples to provide a sample profile and establish a physicochemical basis of comparison for the interpretation of existing and future DEP health effects data. In this regard, standard reference materials (SRMs) of DEPs (SRM 2975) have been certified by the National Institute of Standards Technology (NIST, Gaithersburg, MD, USA) for use in the development, evaluation, and certification of analytical methods for complex environmental diesel mixtures. The composition of NIST SRM 2975 is in Appendix A.

\subsubsection{Health effects and Experiments on Rats}

Ultrafine or nanoparticles (size $<0.1 \mu \mathrm{m}$ ) are reported to produce enhanced levels of lung inflammation, fibrosis, and tumor responses when compared with fine-sized particles (size range $>0.1 \mu \mathrm{m}$ to $2.5 \mu \mathrm{m}$ ) of similar or identical composition (Donaldson, K., et al, 1998 [3] and Oberdorster 1996, 1992, 2002 [4, 5, 6]). The total lung toxicity database for comparing the effects of ultrafine or nanoparticles versus fine-sized particles consist primarily of studies on three particle-types, titanium dioxide $\left(\mathrm{TiO}_{2}\right)$, carbon black, 
and diesel particles (Lee, K. P., et al, 1985, 1986 [7,8], Ferin, J., et al, 1992 [9], Heinrich, U., et al. 1986, 1997 [10,11], Dasenbrock, C., et al 1996 [12], Driscoll, K. E., et al 2000 [13], Mauderly, J. L. 1997 [14]). The rat is a sensitive species for developing adverse lung responses to particles. Evidence from several studies suggests that the mouse and hamster do not develop lung tumors following high-dose, long term exposures to low toxicity dusts (Hext, P. M. 2005 [15]). Recent reports suggest that rat lungs process inhaled particles very differently compared with larger mammals, such as dogs, primates, or humans (Snipes, M. B.1996 [16], Nikula, K. J., et al 1995 [17]). From this, studies in coal miners suggest that long-term occupational exposures to coal mine dust do not result in particle overload-related to tumors in humans. Following inhalation of particles into the lung, the rat demonstrates a faster particle clearance pattern, along with a greater proportion of the retained dust burden being contained within alveolar macrophages (the defense cell-type of the lung) compared with large mammalian species. Although the particle deposition/clearance mechanisms have not been elucidated for large mammals, it seems clear from the limited evidence available in autopsy lung samples of coal miners and the few studies in particulate-exposed primates that the lungs of larger mammals are less reactive to the dust burden insult when compared with results from experimental toxicity studies in rats.

Rats are studied, in large part, because of their enhanced lung sensitivity to particulates and, in toxicity studies, are often exposed to materials of interest at very high exposure concentrations. While this provides estimates of potential hazards, it may not be relevant for human exposures. The generation of hazard data in rats provides a margin of 
safety when attempting to develop risk assessments for human exposures to various particulate materials.

Based on three particle-types, hazard studies in rats demonstrate that ultrafine or nanoparticles administered to the lung produce more potent adverse effects in the form of inflammation and subsequent tumors compared with larger-sized particles of identical chemical compositions. Surface properties, such as surface chemistry and area, may play a significant role in nanoparticles toxicity (Warheit, D. B., et al 2005 [18]). The very high size-specific deposition of nanoparticles when inhaled as singlet ultrafine particles rather than aggregated ones also contributes to their effect. Some evidence suggests that inhaled nanoparticles, following deposition in the alveolar regions of the lung, largely escape lung defense surveillance and transmigrate from airspace to the interstitial regions of the lung, considered to be a vulnerable anatomical compartment in the respiratory tract (Donaldson, K., et al, and Oberdorster, G., Philbert 1995 [19]).

Ultrafine particles have a high specific area, which can catalyze reactions and absorb high amounts of toxic substances (like Polycyclic Aromatic Hydrocarbons), making them a carrier into the deep lung during inhalation (Seaton et al., 1995 [19]). They have higher deposition probability particularly in the small airways and the alveolar region of the lungs (Bair et al., 1974 [21]). They induce more oxidative stress than fine particles (Stone et al., 1998, 2001 [22]). They affect immunity (Behrendt \& Becker, 2001 [23]). They inhibit macrophage mobility (Moller et al., 2002 [24]). They have access to systemic circulation (Nemmar et al., 2002 [24]; Oberdorster et al., 2002 [26], Kreyling et 
al., 2002 [27]). They cause more inflammatory effects than larger particles (Donaldson et al., 2001 [28]). They may form complexes with similar sized proteins and biomolecules which may result in functional changes of the latter (Kreyling 2004 [29]). They adversely affect cardiac functions and vascular homeostasis (Stone \& Godleski, 1999 [30]). They have greater access to interstitial spaces than larger particles (Stearns et al., 1994 [31]; Oberdorster et al., 2000 [32]).

\subsection{Measurement of Particulate Matter}

Mass measurements are made in two different ways - directly or indirectly. They are also called "reference" and "equivalent" methods respectively.

Direct (manual) measurements of particulate matter (PM) concentration in the ambient air are made by collecting particles on a filter, which is weighed before, over a specified period of time and then the mass of the particulate matter is calculated gravimetrically. The average ambient concentration over the period is also calculated.

Indirect measurements are made using parameters other than mass that can be converted to units of mass concentration based on known relationships between the two parameters. The main advantage of this over reference methods is equivalent methods provide real-time measurements. This feature is important when parameters such as diurnal variation in concentration or the change in concentration associated with certain activities are of interest. These equivalent methods (indirect measurements) are instrumental and provide continuous measurements of ambient PM concentration. EPA has approved two different methods 

a) Beta-radiation
b) Oscillating pendulum

\section{(i) Beta attenuation monitor}

This is also known as the beta-gauge monitor. They have been used in Europe and Japan for several years. Mass determination is based on the attenuation that a beta-ray particle undergoes as it passes though an exposed filter. The beta attenuation monitor can provide hourly PM concentrations, but it is a very expensive instrument and has a number of operational constraints.

\section{(ii) Tapered Element Oscillation Microbalance (TEOM)}

Principle: PM accumulations on a filter will result in changes to the oscillation frequency of a tube attached to the filter.

It operates $24 \mathrm{hr}$ a day and is automated, requires much lesser labor for intensive continuous measurement of PM concentrations. It collects the particles by a vibrating collection substrate.

It can measure particles in the concentration range from $5 \mu \mathrm{g} / \mathrm{m}^{3}$ to several $\mathrm{mg} / \mathrm{m}^{3}$. Changing the inlet heads, it can be used to measure PM10, PM2.5, PM1, and TSP concentrations. The lowest averaging time in TEOM is 10minutes and it updates for every 2 seconds.

The instrument calculates mass rate, mass concentration, and total mass accumulation on exchangeable filter cartridges that are designed to allow further 
chemical and physical analysis. It provides hourly and daily averages also. The particles are continuously collected on a filter cartridge mounted on the tip of a tapered hollow glass element. This glass element is operated in electric field. With this, particle-carrying air enters through an air inlet and then passes to the sensor unit containing the patented microbalance system.

The sample stream passes into the microbalance system, which consists of a filter cartridge ( 0.5 inch diameter) and oscillating hollow tube. The filter cartridge is a 0.5 " diameter, thin aluminum base (foil-like) assembly. The air stream is heated to a predetermined temperature there. A water resistant plastic cone, which fits onto the oscillating element, is attached to the aluminum base. An automatic flow controller pulls the sample stream through the monitor at flow rates between 0.5 and $5 \mathrm{~L} / \mathrm{min}$. The wider end of the hollow element is fixed to a platform and is vibrated at its natural frequency. The oscillation frequency of the glass element is maintained on the feedback signal from an optical sensor. As the mass accumulates on the filter cartridge, the resonant frequency of the element decreases, resulting in a direct measurement of inertial mass. Based upon the direct relationship between mass and frequency, the monitor's microcomputer calculates the total mass accumulation on the filter, the mass rate and mass concentration in real-time.

It does not require recalibration as it is designed and constructed with non-fatiguing materials. Its mass calibration can be verified by an optional mass calibration verification kit that contains a filter of known mass. Active volumetric control is maintained by mass 
flow controllers whose set points are constantly adjusted in accordance with the measured ambient temperature and pressure. The TEOM monitor is very sensitive to mass concentration changes and can provide precise measurements for sampling durations of one hour or less. For this, the hollow glass element must be maintained at a constant temperature to minimize the effects of thermal variations.

Table 2 Specifications of TEOM: (from Thermo Scientific)

Website: http://www.thermo.com/com/cda/product/detail/1,10122682,00.html)

\begin{tabular}{|l|l|}
\hline Precision & $\begin{array}{l} \pm 1.5 \mu \mathrm{g} / \mathrm{m} 3 \text { (1-hour ave), } \pm 0.5 \mu \mathrm{g} / \mathrm{m} 3 \text { (24-hour } \\
\text { ave) }\end{array}$ \\
\hline Minimum Detectable Limit & 10 nanograms, $0.06 \mu \mathrm{g} / \mathrm{m} 3$ (1-hour ave) \\
\hline $\begin{array}{l}\text { Accuracy for Mass } \\
\text { Measurement }\end{array}$ & $\pm 0.75 \%$ \\
\hline Main Flow Rate & 0.5 to $41 / \mathrm{min}$ \\
\hline Auxiliary Flow Rate & 2.0 to $18.01 / \mathrm{min}$ \\
\hline Data Storage & $\begin{array}{l}\text { Up to } 40 \text { weeks of hourly mass concentration } \\
\text { data }\end{array}$ \\
\hline Data Output and Input & $\begin{array}{l}2 \text {-way RS-232 Communication, } 3 \text { User-Defined } \\
\text { Analog Outputs, } 7 \text { Averaged Analog Inputs }\end{array}$ \\
\hline Operating Range & $\begin{array}{l}\text { Sampled Air - } 40 \text { to } 60^{\circ} \mathrm{C} \text {. Control and Sensor } \\
\text { Units must be weather protected within the } \\
\text { range of } 2-40{ }^{\circ} \mathrm{C}\end{array}$ \\
\hline Power Requirement & $\begin{array}{l}\text { Sensor and Control Units and Sampling Pump: } \\
120 \text { VAC/60Hz: } 5.25 \mathrm{~A} ; 240 \text { VAC/50 Hz, 3.25A }\end{array}$ \\
\hline
\end{tabular}




\begin{tabular}{|l|l|}
\hline Dimensions, Sensor Unit & $\begin{array}{l}\text { Base W: 14" (36cm) x D: 11" (28 cm) x H: 13" } \\
(33 \mathrm{~cm}) . \text { Heated Air Inlet H: 26" (66 cm) x Dia } \\
3.5^{\prime \prime}(9 \mathrm{~cm})\end{array}$ \\
\hline Dimensions, Control Unit & W: 17" (43cm) x D: 18" (46 cm) x H: 9" $(22 \mathrm{~cm})$ \\
\hline Weight & $\begin{array}{l}\text { Sensor Unit: } 40 \mathrm{lb}(18 \mathrm{~kg}), \text { Control Unit: } 32 \mathrm{lb} \\
(15 \mathrm{~kg})\end{array}$ \\
\hline
\end{tabular}

Sensor Unit is kept inside the Test Chambers. Control Unit is kept outside the Test Chamber.

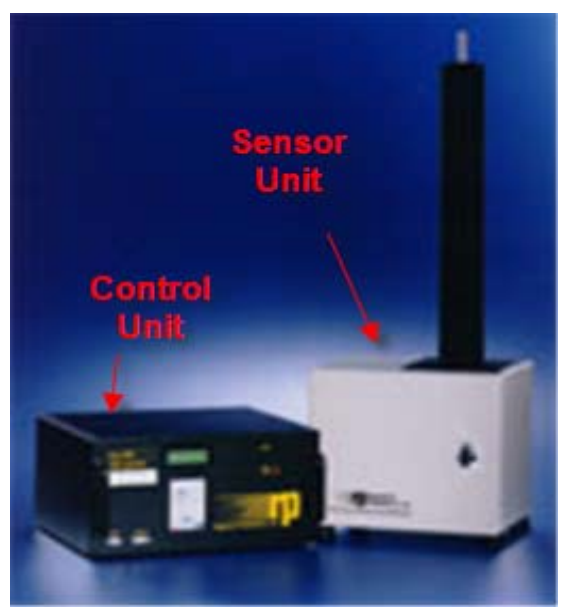

Figure 2.1 TEOM Series 1400ab Ambient Particulate Monitor

\subsection{Inhalation System}

For determination of usage of DEP dust required for carrying controlled inhalation experiments to investigate the effects of DEP on animal samples, a real time inhalation testing equipment was set up in whole body Small Animal Inhalation Testing 
Facility at West Virginia University. For experimentation in this inhalation testing facility, NIST SRM 2975 dust has been used to replace the much expensive DEP dust.

\subsubsection{Construction of Inhalation system}

The inhalation chamber mainly consists of two Hazelton testing chambers connected to fresh air. Out of these Control Inhalation Chamber is connected only to the fresh air maintaining healthy and amicable atmosphere to the animal samples and the Test Inhalation Chamber is used for carrying DEP dust inhalation. This Test Inhalation Chamber is connected to fresh air and also to a duct carrying NIST SRM 2975 dust driven by a jet mill. These two chambers facilitate the researchers to understand the effect of DEP dust on lungs of animal samples by creating clean environment in one chamber and environment contaminated with DEP dust in the other. Other accessories included in the testing system are air filters, a vibrator feeder, a muffler and an electro static neutralizer. The applications of these accessories are discussed below. Along with the accessories to run the experiment a Tapered Element Oscillation Microbalance (TEOM) to measure the concentration of the dust in the chamber is housed in the Hazelton inhalation testing chamber and a probe connected to i-server temperature humidity measuring device is introduced into the chamber through a hole in the door of the chamber. The entire set up is shown in Figure. 2.2 


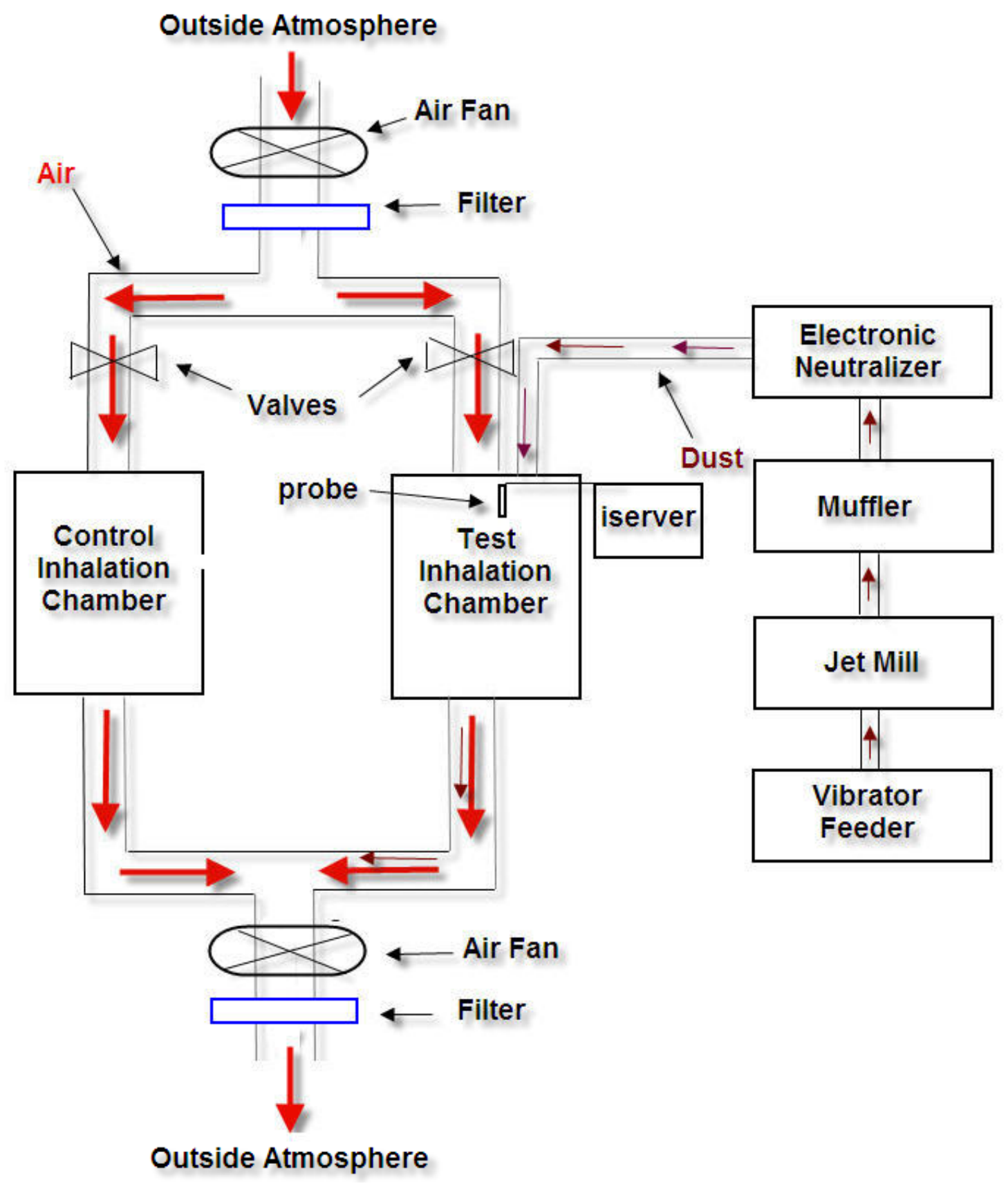

Figure 2.2 Front View of Inhalation System

Hazelton Chamber: An H-2000 Hazelton chamber has been used for this process. This chamber is designed to provide uniform aerosol mixing, protect each level from excreta of animals on other levels, allow efficient set-up and shut-down of inhalation studies. 
This chamber provides a volume of $2.1 \mathrm{~m}^{3}$ and capable of housing six inhalation cages to accommodate 24 rats/cage. Generally, these chambers maintain uniform distribution throughout the entire chamber, creating a uniform test atmosphere of $100 \%$ concentration within 15 minutes.

Jet mill: The jet mill is attached to pressurized air source which maintains the grinding and pusher nozzles at 80 PSI. The particles are fed through feed inlet and the high turbulent stream will pulverize the particles into small particles. Larger particles will recycle while smaller particles will leave the jet mill.

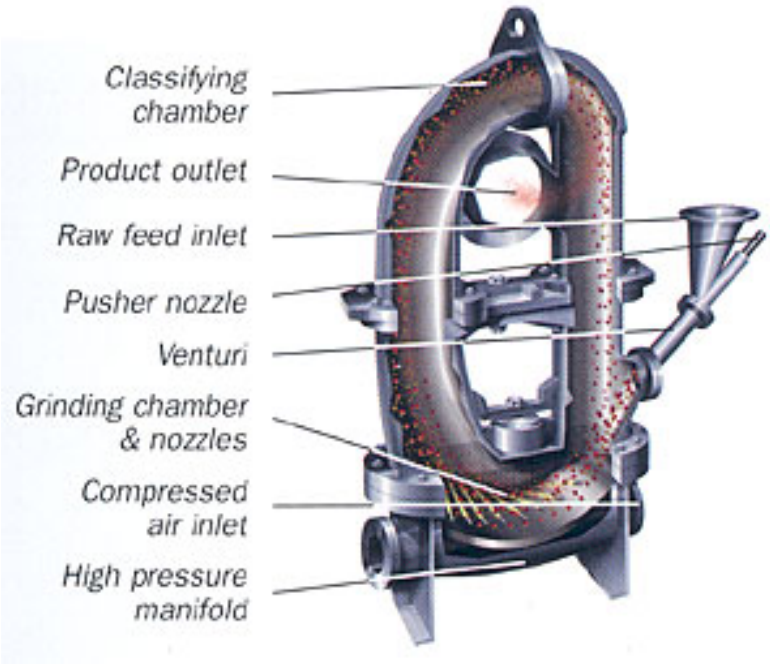

Figure 2.3 Jet Mill

(Courtesy: Fluid Energy Equipment Division Company)

\section{Figure 2.3 Side View of Inhalation System Schematic Diagram}

Filters: The filters in the setup are used for taking in dust free fresh air from the atmosphere and the filters located downstream are used for filtering out the dangerous NIST dust introduced into the testing chamber thus releasing dust free air into the outside atmosphere. 
Vibrator Feeder: Vibrator feeder is used for controlled feeding of dust into the jet mill and is maintained manually.

Muffler: An automobile muffler was used in the system to reduce the noise generated by the jet mill during the experiment.

Electrostatic Neutralizer: An electro static neutralizer was used to remove any static charges that could cause the particles to aggregate and increase the coarseness of the aerosol.

\subsubsection{Working of Inhalation Testing System}

The outside air in the atmosphere is pulled through the air filters using the air fan located on the top of the chambers. This air is supplied to both control and testing chambers. NIST dust is supplied to the vibrator feeder and it routes the dust to the jet mill for aerosolizing into particulates. These aerosolized particulates are sent to the Hazelton testing inhalation chamber through the electro static neutralizer for static free particulates. The air from outside atmosphere mixes with the NIST dust and then passes out through the filter located in the bottom of the chamber where another fan sucks the air out into the atmosphere. 


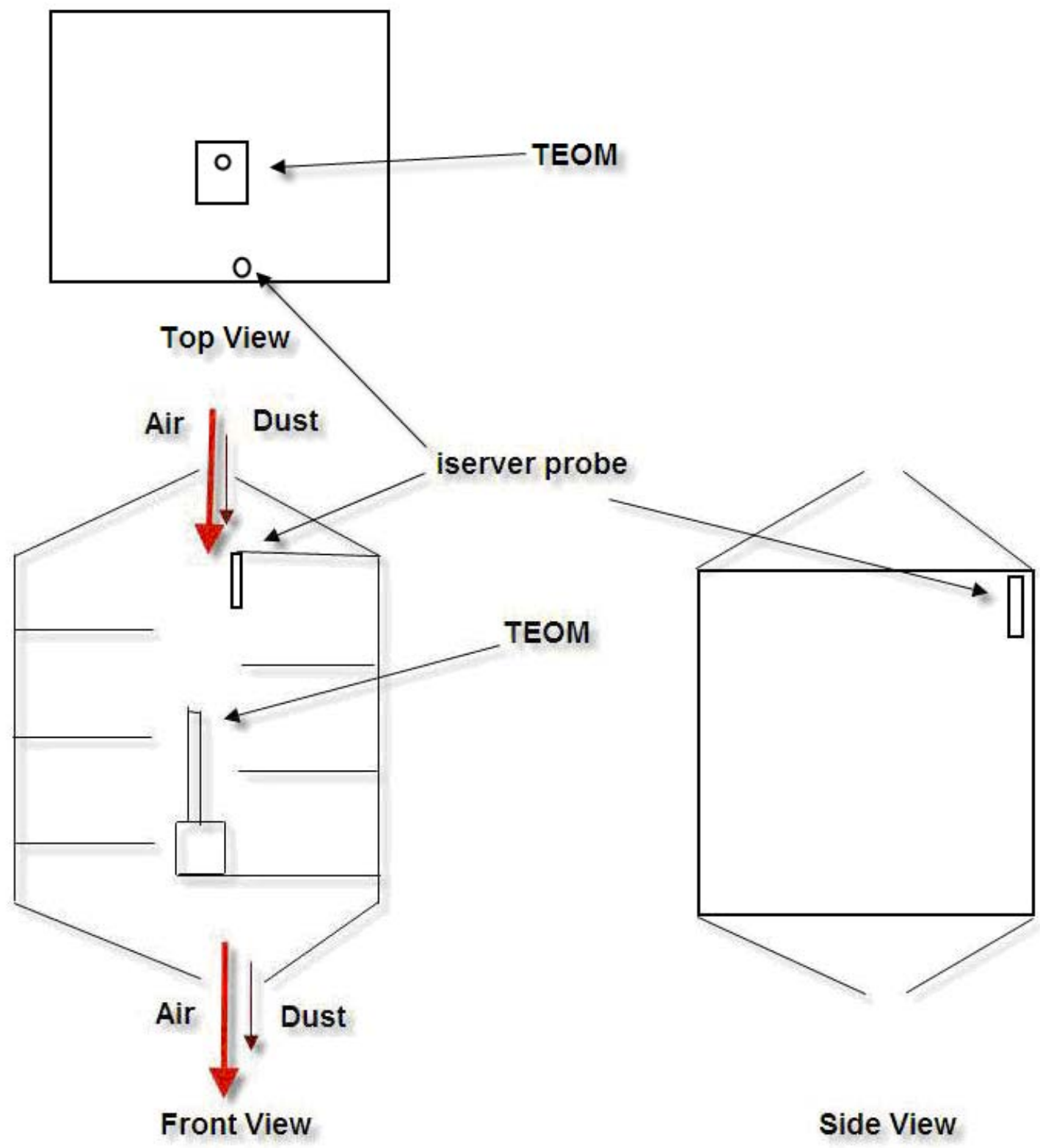

Figure 2.4 Hazelton Inhalation Exposure Chamber 


\section{EXPERIMENTAL PROCEDURE}

\subsection{Monitoring Temperature and Humidity using i-Server}

The objective of this section is to monitor the temperature and relative humidity of the inhalation system 24 hours/day through internet access using the Omega iTHX-5 temperature and humidity probe. An alarm message would be activated if the temperature exceeded approximately $70^{\circ} \mathrm{F}$ or the relative humidity exceeded approximately $50 \%$. The alarm would be transmitted via internet to a pager.

The Omega iServer is used to monitor and record temperature, relative humidity, and dew point over an Ethernet network or the Internet. The iServer allows active web pages to display real time readings, display charts of temperature and humidity, or log data in standard data formats.

There are two channels to connect two probes on the iserver. Only one probe was used for this study and it was connected to channel 2. There are four pins in each channel numbered accordingly. Channel 1 contains pins from 1 to 4 and Channel 2 contains pins 5 to 8 . The cable connecting the probe contains 4 different colors of wires and one wire as a shield.

According to the manual, pin\#5 is connected to the red wire (voltage supply), pin\#6 to black (GND), pin\#7 to green (SCK- signal clock), and pin\#8 to the white wire. There is a reset button used for power resetting the iServer.

The Omega IDRN-PS-1000 universal switching power supply (shown in Figure 4) was provided to supply well-regulated 24 volt DC power to the iServer (shown in Figure 5). There should be a minimum of 1" spacing from this power supply unit to any 
other unit to allow sufficient air circulation for proper cooling. The connections are made as shown in Figure 3.

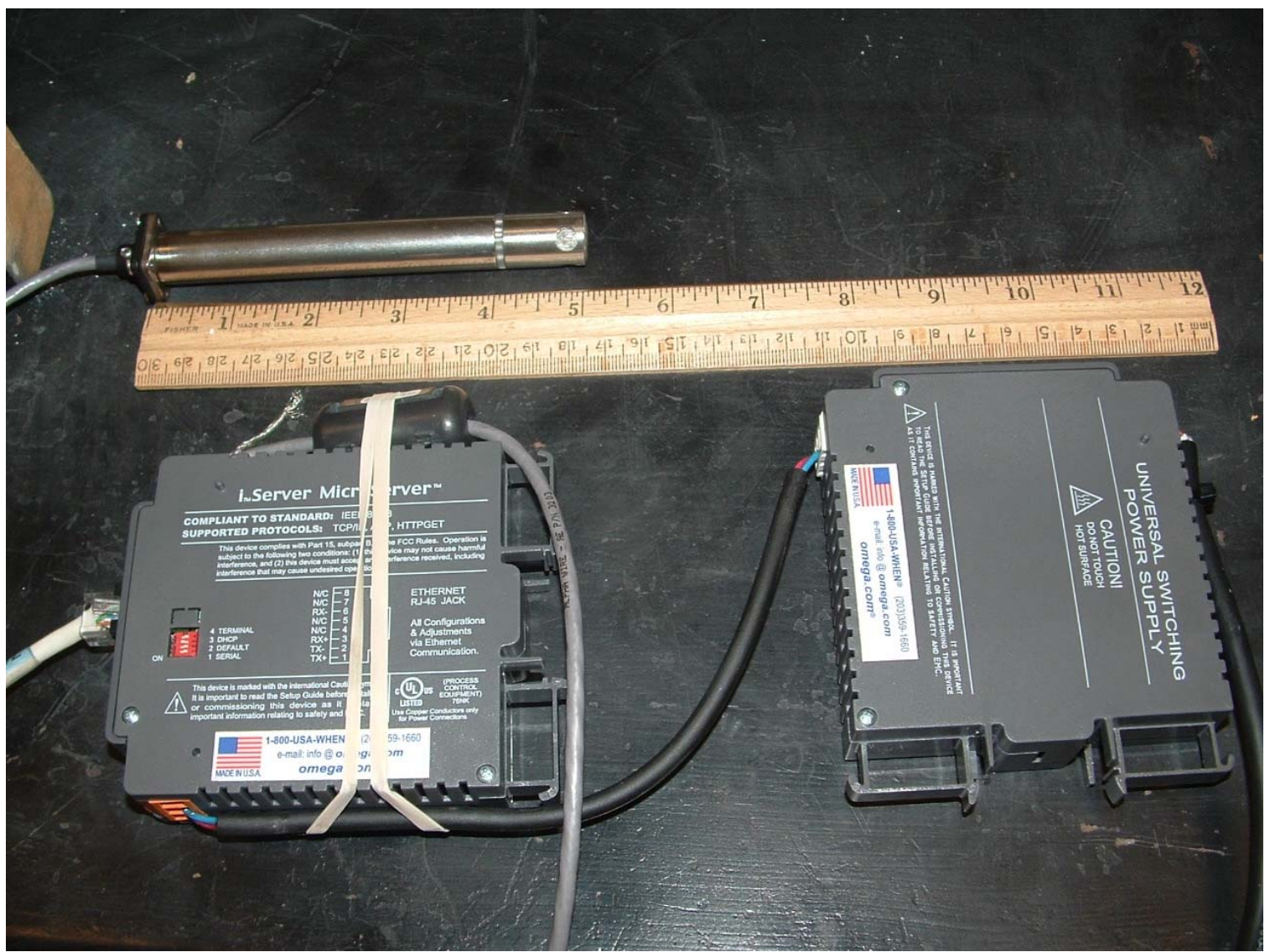

Figure 3.1 iServer on the left and Power supply on the right 


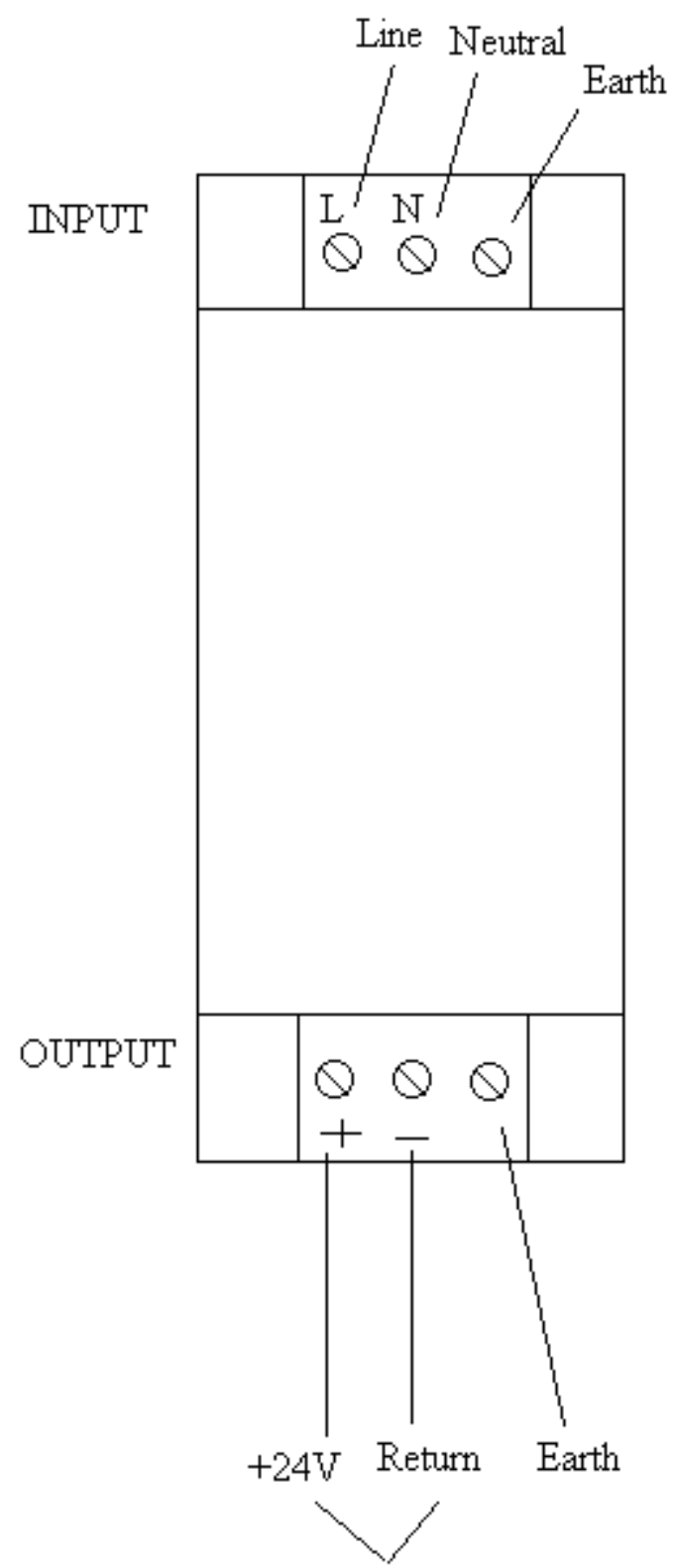

To signal conditioner modules

Figure 3.2 Input/Output Connections of IDRN-PS-1000 Power Supply unit

Wiring for 115 V ac - Single Phase 


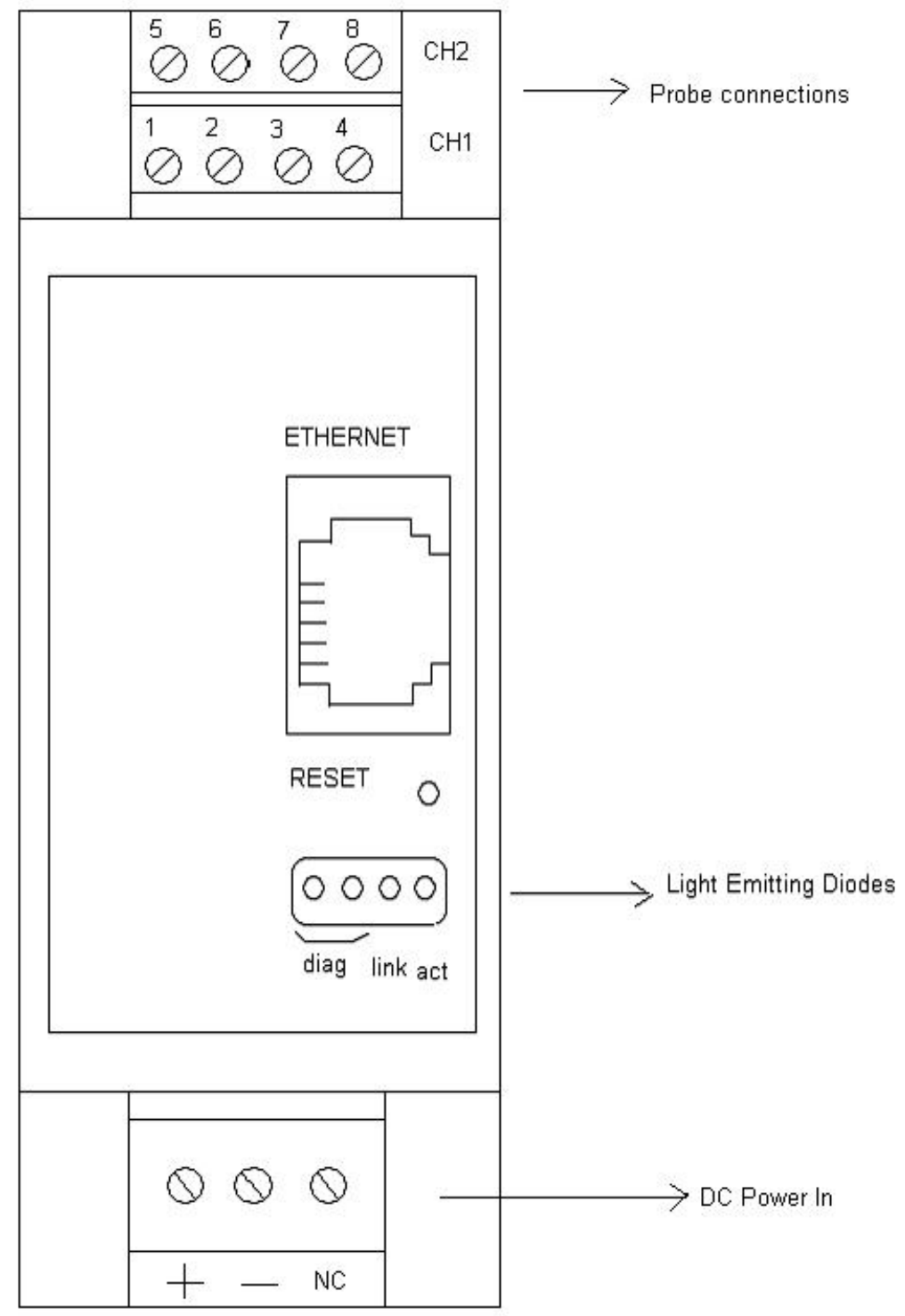

Figure 3.3 Parts of iServer unit

The light emitting diode has the following functions:

DIAG: LED (Yellow) Blinking: For diagnostics, indicates DHCP when first connected DIAG: LED (Green) Blinking: For diagnostics, indicates DHCP when first connected. NET LINK: LED (Green) Solid: Indicates good network link 
ACTIVITY: LED (Red) Blinking: Indicates network activities (receiving or sending packets)

Every machine on the internet has a unique identifying number, called an internet protocol (IP) address. The IP address of the iServer was assigned 157.182.80.181. This was assigned as the instrument should be in the same range as the IP address of computer accessing it. The computer IP address was 157.187.81.41. When the internet browser is opened with the above IP address, the page looks like the following

\section{SERVER HOME PAGE}
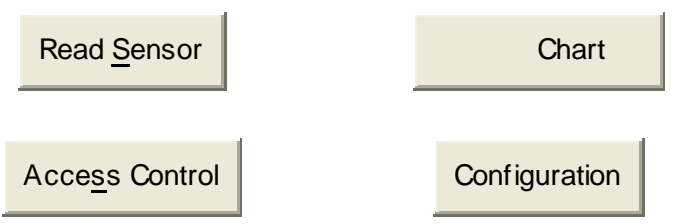

When any options of the four is clicked for accessing data, a login password is asked for.

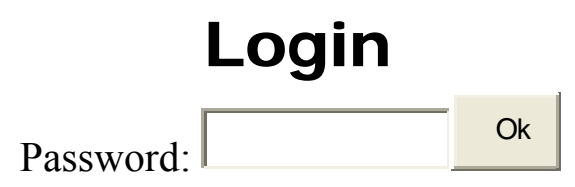

When Read Sensor is clicked, a new web page is opened giving the temperature, humidity, and dew point values for both channels.

Channel 2 monitors the temperature and humidity of the sensor. 


\section{iSever}

\section{$\mathrm{CH} 2$ Temperature $\quad 70.00{ }^{\circ} \mathrm{F}$ \\ $\mathrm{CH} 2$ Humidity $\quad \mathbf{5 0 . 0 0 \%}$}

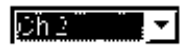

When the Chart option is chosen from the main menu, a new web page is opened displaying the Temperature vs. Time and Relative Humidity vs. Time charts as shown in Figure 6. Options are available for displaying temperature units in ${ }^{\circ} \mathrm{C}$ or ${ }^{\circ} \mathrm{F}$.

At the bottom of the chart, options are there for the displaying X-axis for one minute, one hour, one day, one week, one month, or one year.

Note: In Figure 6, channel 1 displays some default reading even though it was not connected. In Figure $6 \mathrm{X}$ axis represents the time period (i.e. 1.15 minutes) and the $\mathrm{Y}$ axis has been shared by temperature and relative humidity and for temperature readings each dimension represents $9^{\circ} \mathrm{C}$ difference in temperature and for relative humidity each divisions represents $10 \%$ difference in relative humidity. 


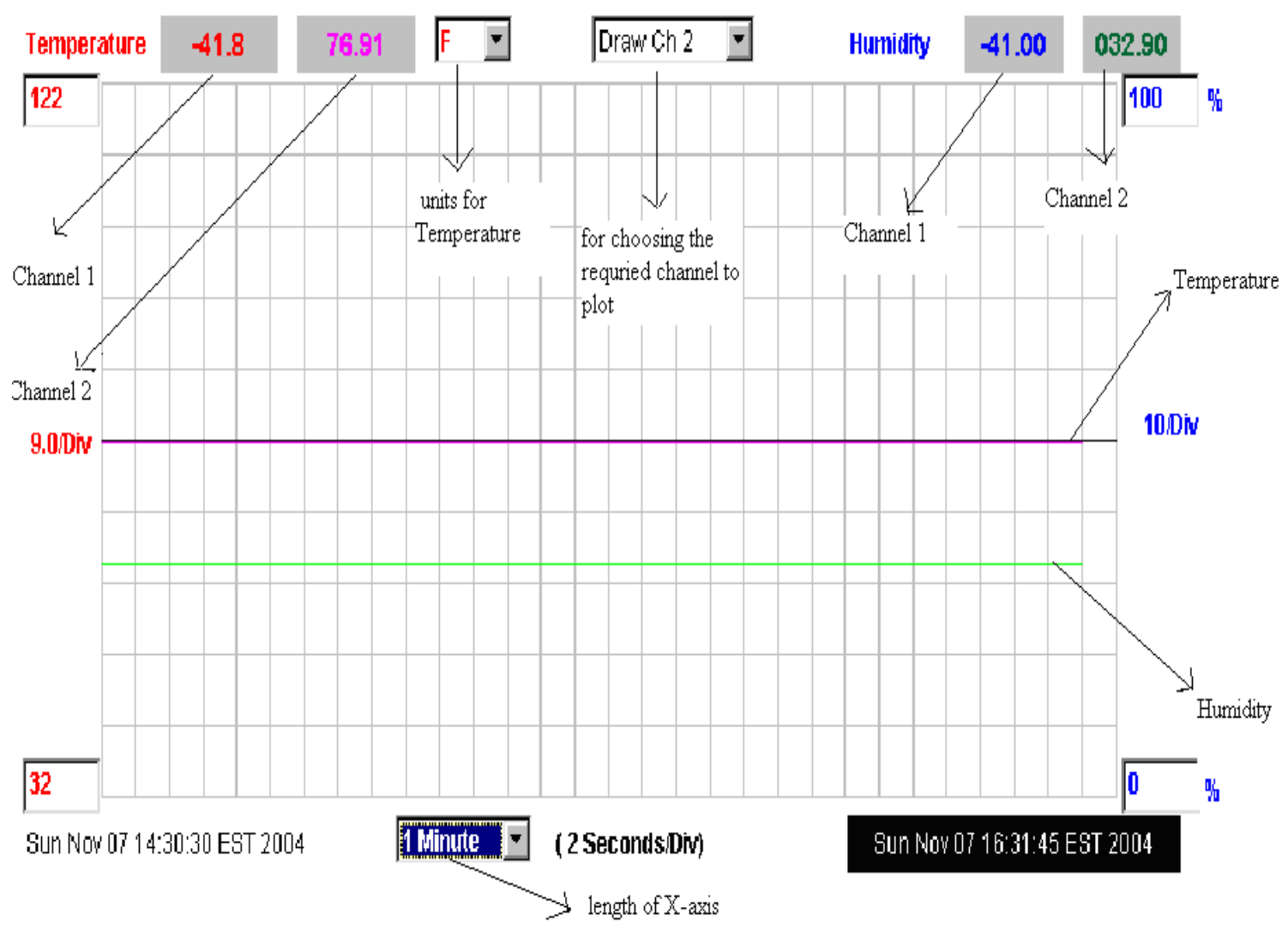

Figure 3.4 Chart displaying Temperature vs. Time and Humidity vs. Time

\subsubsection{Mail Notifier}

The Mail notifier software runs on a computer in the lab and utilizes E-mail notifications of alarm conditions of the devices connected to the Ethernet. The user can be automatically notified of alarm conditions monitored via internet connections throughout the world. The Mail Notifier utility operates under Windows 95, 98, NT 4.0 and NT 2000 in conjunction with existing E-mail that supports the MAPI (Messaging 
Application Programming Interface) messaging interface. MAPI is a messaging architecture and a client interface component and it enables multiple applications to interact with multiple messaging systems across a variety of hardware platforms. Network access must be available between the computer and the iServer. Network access must also be available from the computer to the appropriate E-mail server and from the E-mail server to the recipient's E-mail server.

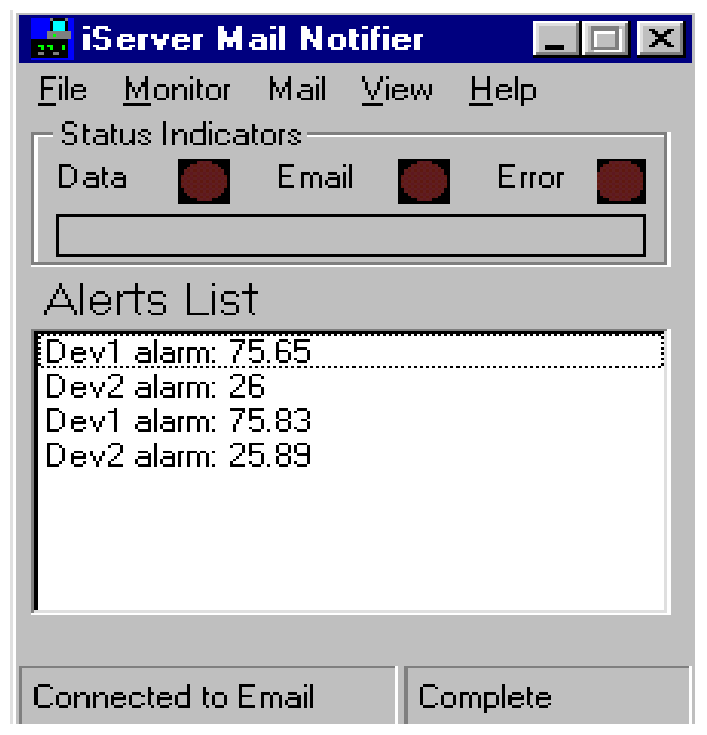

\section{Figure 3.5 iServer Mail Notifier Main window}

The alarm editor has 3 alarm types for temperature and humidity. The alarm editor for temperature was shown in Figure 8. For testing, the alarm high was set to $70^{\circ} \mathrm{F}$. This gave an alarm (message) when temperature was above 700F. The alarm can also be setup for alarm low which gives an alarm when the temperature drops below that value. The third type is Band which gives an alarm when the temperature goes above or below set temperature and humidity values. 
There are two interval options to be setup - pause interval and monitor interval. Pause interval is the time interval between two successive alarms. Monitor interval is the time interval for which the software checks with the iServer. The units for these intervals are seconds.

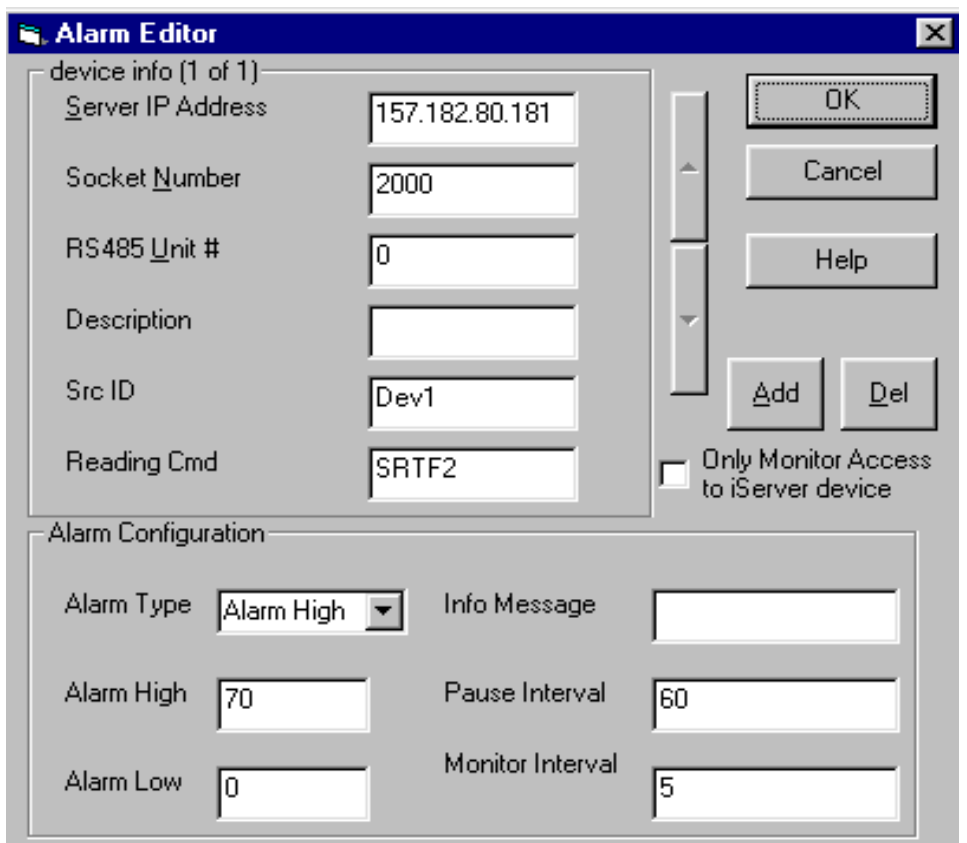

\section{Figure 3.6 Setup and Configuration for Mail Notifier Software}

\subsection{Controlling the Humidity}

The objective here is to monitor and maintain the relative humidity at 50\% ( \pm $2 \%)$.

Relative Humidity Monitoring: The relative humidity in the inhalation chamber is measured by Ohmic model SCE 5/90 Environmental Humidity Monitor which can precisely monitor the relative humidity percentage within $\pm 1 \% \mathrm{RH}$. These measurements are selectably displayed on a $3.5^{\prime \prime}$ - digit LED readout on the front panel and is continuously available as analog voltages at a 9-pin D-type Amphenol output connector 
on the bottom panel. This connector provides analog output voltage for the humidity. The humidity output is a 0 to 5 volt span (equivalent to $0-100 \% \mathrm{RH}$ ).

A 9-pin male connector wire is connected here for the output signal. This contains three wires: black (common), red (relative humidity), and green (temperature). Here black and red wires were used as relative humidity was only controlled.

There is RTI - 800/815 (12-bit) data acquisition board which is connected to the PC. These boards are used to provide a direct interface between the PC and the analog/digital world for a variety of data acquisition, analog output, digital I/O, and counter-timer I/O applications. The RTI $-800 / 815$ is a multifunction data acquisition board that has capabilities for various modes of analog/digital input/output operation.

Analog input/output applications are connected to the RTI - 800/815 through the 50-pin male connector. There are 16-single channels on the board for the analog input connection.

Channel 0 was chosen for analog input connections. For Channel 0, pin 3 is high and pin 19 is low. The red wire was connected to pin 3 and black wire was connected to pin 19.

From the input voltage, the digital output signal is controlled by LABTECH software program on the computer. 
Voltage switch is connected to between the humidifier and it's current supply. The analog output voltage is connected in the circuit to this resistor. This switch operates between works 0 to $2.5 \mathrm{~V}$. If the voltage goes above $2.5 \mathrm{~V}$, the switch gets disconnected and the power supply stops for the humidifier.

\subsection{Concentration Measurement}

The procedure here consists of 3 parts:

1) To find the amount of NIST 2975 DEP dust required to maintain the dust concentration in the inhalation chamber at $20 \mathrm{mg} / \mathrm{m}^{3}$ for 4 hours at 10 volume/ hour air change.

2) Determine the effect of number of air changes per hour on the concentration

Before recording the concentrations, the vibrator feeder was monitored and adjusted until the Tapered Element Oscillating Microbalance (TEOM) reading stabilized around the required concentration. Real time graphs are displayed on the computer with mass concentration on the $\mathrm{Y}$-axis and time on the $\mathrm{X}$-axis.

The pusher nozzle and grinding nozzle of the vibrator feeder were maintained at 80 psi ( \pm 5 psi). The humidity inside the chamber was maintained around $50 \%$. Temperature was maintained around $70^{0} \mathrm{~F}$.

The cap for the inlet pipe in the inhalation chamber needs to be cleaned before starting the experiment. 


\section{EXPERIMENTAL RESULTS AND DISCUSSIONS}

The main objectives of this investigation includes simultaneous monitoring and controlling of the relative humidity and temperature of the inhalation testing chamber, and to measure the amount of DEP dust required to maintain the testing chamber with certain concentration of DEP with air changes per hour changing air volume cycles and relative humidity.

\subsection{Monitoring the Relative Humidity and Temperature of the Inhalation Chamber}

Monitoring the relative humidity and temperature of the inhalation chamber has been carried using Omega iTHX-5 temperature and humidity probe. The data collected from this probe was collected by i-server and then sent to user email address as an alert. This equipment was tested in three different ranges.

Firstly, the equipment was tested for upper range alerting system, i.e. the alerting system was so defined such that an email alert will show up only upon increase in relative humidity and temperature beyond user defined limits. To test this type of scenario, the relative humidity and temperature of the inhalation chamber was set to $70^{\circ} \mathrm{F}$ and $50 \% \mathrm{RH}$ and later the temperature and relative humidity were increased intentionally beyond the defined limits. Upon increase of these factors an email was sent to the user immediately alerting the situation regarding the increase in temperature and relative humidity. Similarly the equipment was tested for lower range humidity and temperatures and also for a "band" range, i.e. the equipment sends alerts if the relative humidity and 
temperature is going below or above the defined limits. The alerting emails showed that the system worked successfully under all three different working conditions.

\subsection{Control of Inhalation Chamber for Relative Humidity and Temperature}

The relative humidity in the chamber is maintained by an air humidifier. A voltage switch was also employed to this air humidifier. Under any condition of increase of relative humidity in the chamber, the voltage switch cuts off the power supply to the air humidifier and hence maintaining the user defined relative humidity in the chamber. As the relative humidity needed for the rat experiment is $50 \%$, the voltage switch $(0-5 \mathrm{~V})$ is closed only when the voltage is equal to or less than $2.5 \mathrm{~V}$. This voltage comes from the output voltage from Ohmic model SCE 5/90 Environmental Humidity Monitor. 0V is equivalent to $0 \% \mathrm{RH}$ and $5 \mathrm{~V}$ is equivalent to $100 \% \mathrm{RH}$.

During the experiment, when the RH was dropped, the voltage switch was closed and in few seconds the RH reached the stipulated limit. As the humidity started to go above $50 \%$ the voltage switch was opened as voltage also went above 2.5 , as expected. This cycle happens quite frequently (for every few minutes) during the experimentation. Through out the period of testing, the RH value was successfully maintained at the user defined limits with the help of voltage switch.

\subsection{Measurement of amount of DEP dust required for varying air volume changes and RH in inhalation chamber}

To facilitate proper oxygen supply to the animal samples (rats) the air inside the testing chamber has to be circulated. So to investigate the effect of change in air/ supply 
of fresh air into the testing chamber, the experimentation has been conducted under different air changes per hour. Depending on the number of rats inside the testing chamber the air changes per cycle would increase with increase in rats.

The air in the inhalation chamber was circulated with fresh air for given amount of volume change called as "number of air changes". Each air change represents circulating the entire volume of the chamber with fresh air. So one air change per hour represents the rate of fresh air coming in and going out of the chamber in one hour is equal to the volume of the chamber.

The chamber was tested for different air changes per hour and the amount of DEP dust required for maintaining the required concentration was measured by weighing the filter which is in TEOM. For maintaining certain concentration during any air change cycle, the process undergoes two phases. One is transient phase during which the concentration increases steadily as the air is circulating through the chamber and the once the required concentration is reached, the rate of DEP input has to be varied to maintain that concentration. This is called steady state phase.

The amount of DEP dust used during transient and steady states gives the total amount of DEP dust required for maintaining the user desired concentration inside the testing chamber during the air changes. 
Different air cycle changes were used in the experiment - 10 air changes per hour and 4 air changes per hour as shown below - to calculate the dust required and the affect of air changes on the dust.

The dust is used from a bottle. It is weighed before the experiment start. After the experiment, the remaining bottle is again weighed to find the dust used in the experiment.

\section{i) 10 air changes/ hour:}

The required concentration was reached in about 13 minutes and needed $0.132 \mathrm{~g}$ of dust to reach this concentration. The steady state in this experiment was maintained for 4 minutes and the amount of dust needed to keep this concentration steady for 4 minutes was $28 \mathrm{mg}$.

From the above, the total amount of dust needed to reach a concentration of 20 $\mathrm{mg} / \mathrm{m}^{3}\left( \pm 2 \mathrm{mg} / \mathrm{m}^{3}\right)$ and to maintain this concentration for 4 hours should be $2.29 \mathrm{~g}$.

\section{ii) 4 air changes/ hour:}

The number of air changes per hour was reduced to 4 volumes/ hour. This concentration was reached in 14 minutes and required $0.083 \mathrm{~g}$ of dust to reach this concentration. After reaching this concentration, this concentration was maintained for 4 minutes and the amount of dust needed for this 4 minutes steady state was $11 \mathrm{mg}$. From the above, the total amount of dust needed to reach a concentration of $20 \mathrm{mg} / \mathrm{m}^{3}( \pm 2$ $\mathrm{mg} / \mathrm{m}^{3}$ ) and to maintain this concentration for 4 hours should be $0.97 \mathrm{~g}$ 


\section{VOLUME CHANGES PER HOUR GRAPHS}

\section{1) 10 air changes per hour}

The following figures show the graphical results of reaching the desired concentration of $20 \mathrm{mg} / \mathrm{m}^{3}$ in the inhalation chamber at 10 air changes per hour and a relative humidity of about $50 \%$.

These graphs show the relation between concentration in $\mu \mathrm{g} / \mathrm{m}^{3}$ and time in hours and minutes with in the first 4 minutes of the experiment. This experiment was done at 10 air changes per hour of air flowing through each inhalation chamber. The experiment was started at time 20:44 where 20 represent the hours and 44 represent the minutes.

Figure 4.1 is the start of the process at time 20:44. The concentration change in the chamber is detected between 20:46 and 20:47. Figure 4.2 and Figure 4.3: They show a continuous increase of concentration in the chambers. Figure 4.4 shows that the concentration is close to $20 \mathrm{mg} / \mathrm{m}^{3}$ between time 20:55 and 20:56. Figure 4.5 shows stabilization of concentration around $20 \mathrm{mg} / \mathrm{m}^{3}$ for 4 minutes. Figure 4.6 shows the stabilization and as no dust is added the concentration drops between time 20:59 and 21:00 as dust was stopped adding. Figure 4.7 shows rapid falling of dust as no further dust is added. 


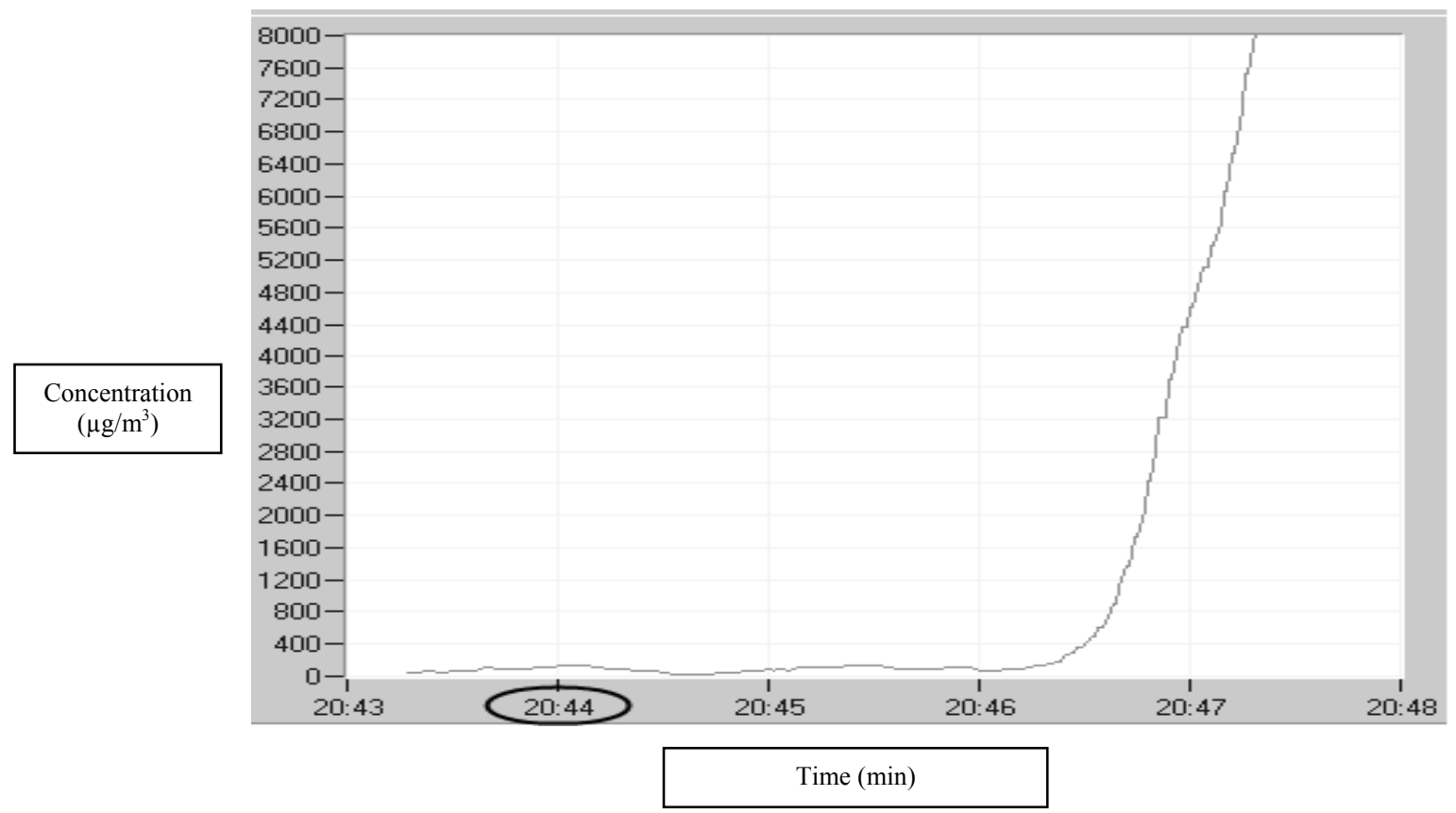

Figure 4.1 The experiment was started at time 20:44 where 20 represent the hours and 44 represent the minutes. The dust was added to chamber at 20:44. The change in the concentration by TEOM was recognized near 20:47

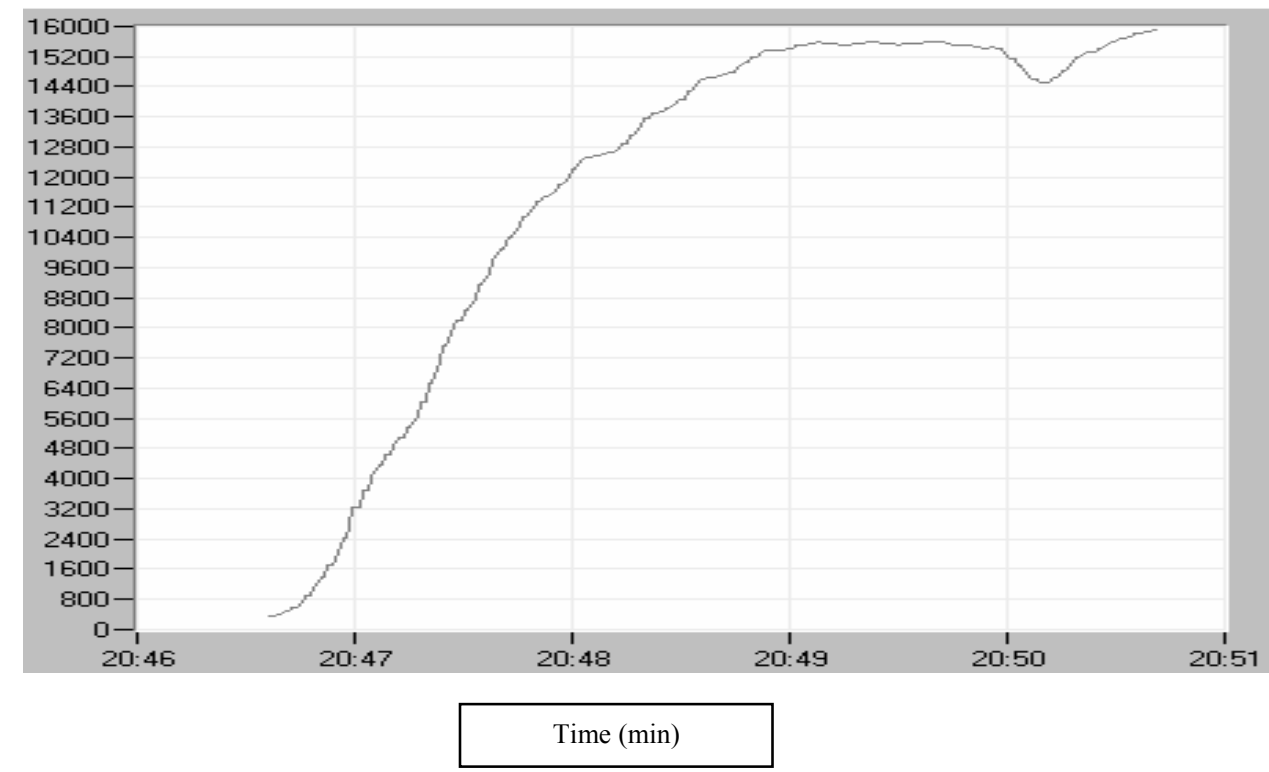

Figure 4.2 This is the continuation of Figure 4.1 showing from time 20.47. The vibrator feeder adds the dust continuously and jet mill pumps the dust into the chamber 


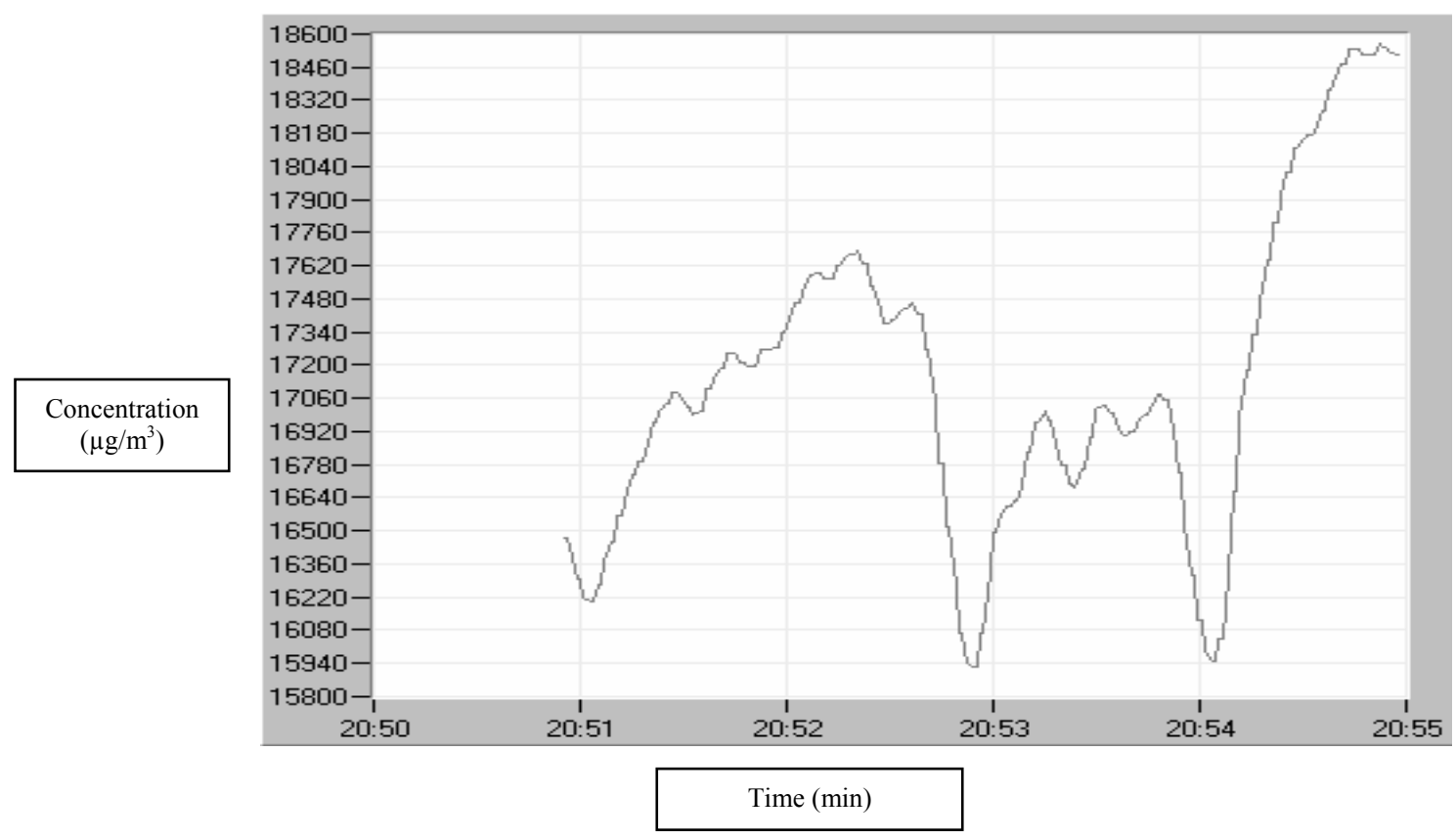

Figure 4.3 This is the continuation of Figure 4.2 showing from time 20.51. The vibrator feeder adds the dust continuously and jet mill pumps the dust into the chamber

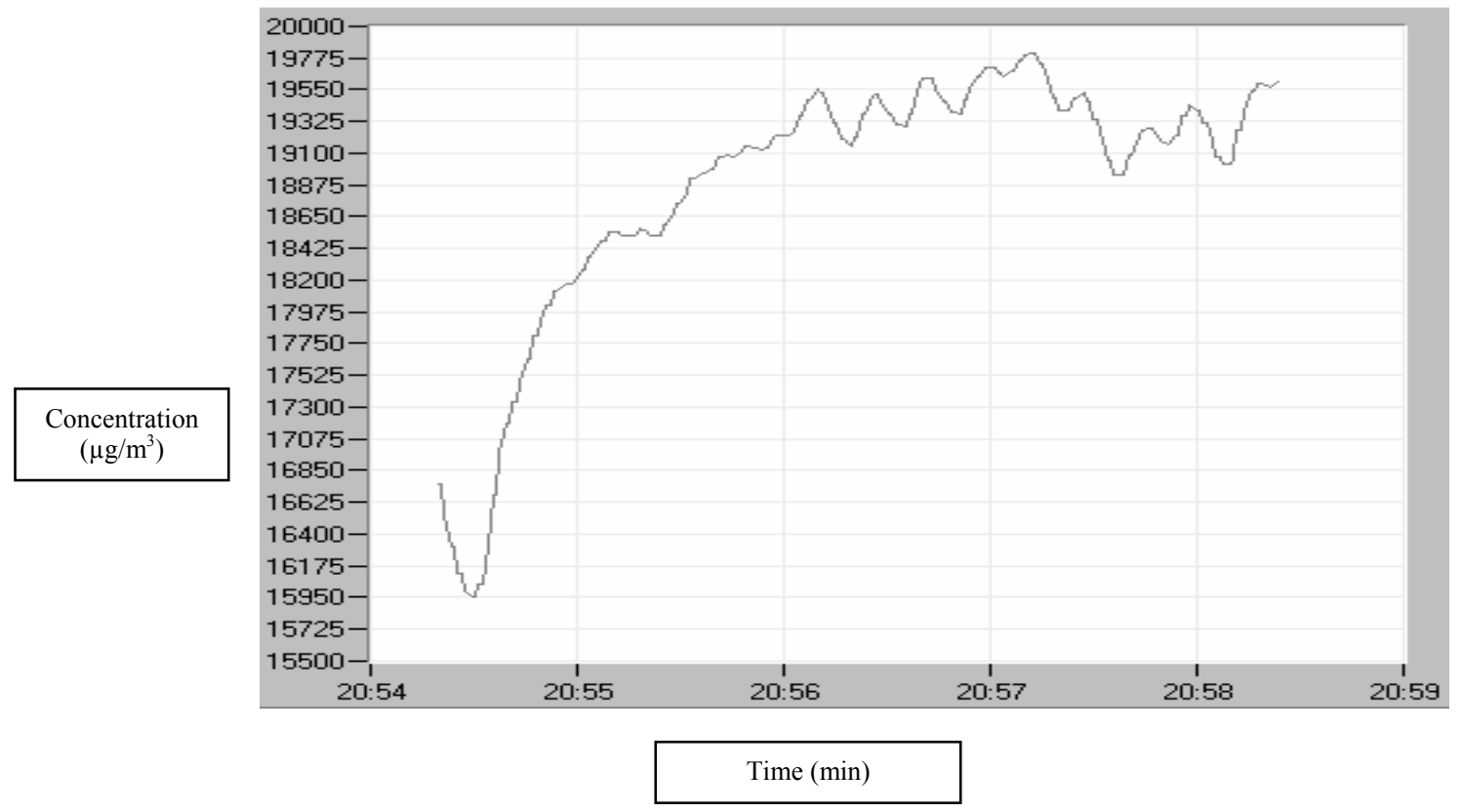

Figure 4.4 This is the continuation of Figure 4.3 showing from time 20.55. As the concentration of dust reaches $20 \mathrm{mg} / \mathrm{m}^{3}$, the feed rate is adjusted manually to maintain the concentration at $20 \mathrm{mg} / \mathrm{m}^{3}$ 
Concentration $\left(\mu \mathrm{g} / \mathrm{m}^{3}\right)$
Concentration $\left(\mu \mathrm{g} / \mathrm{m}^{3}\right)$

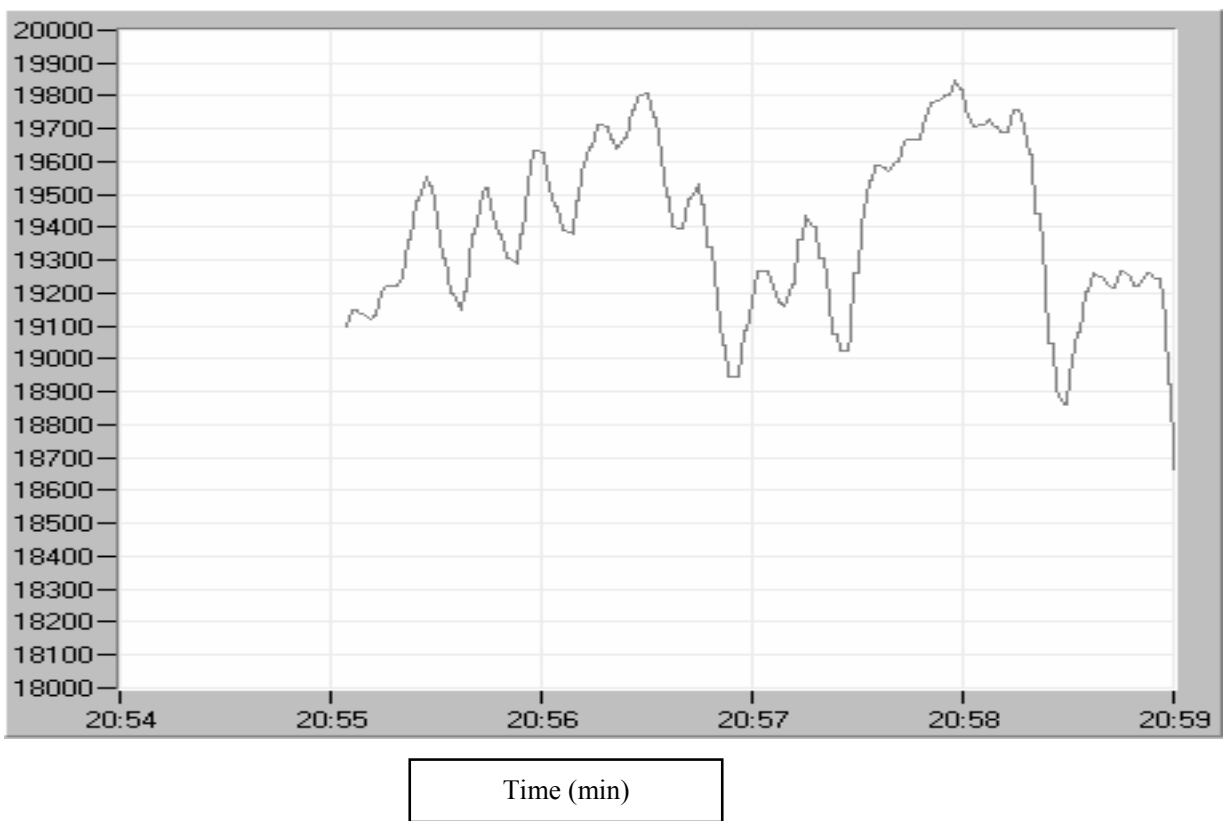

Figure 4.5 This is the continuation of Figure 4.4 showing from time 20.56. The steady concentration of $20 \mathrm{mg} / \mathrm{m}^{3}$ is maintained for $4 \mathrm{~min}$

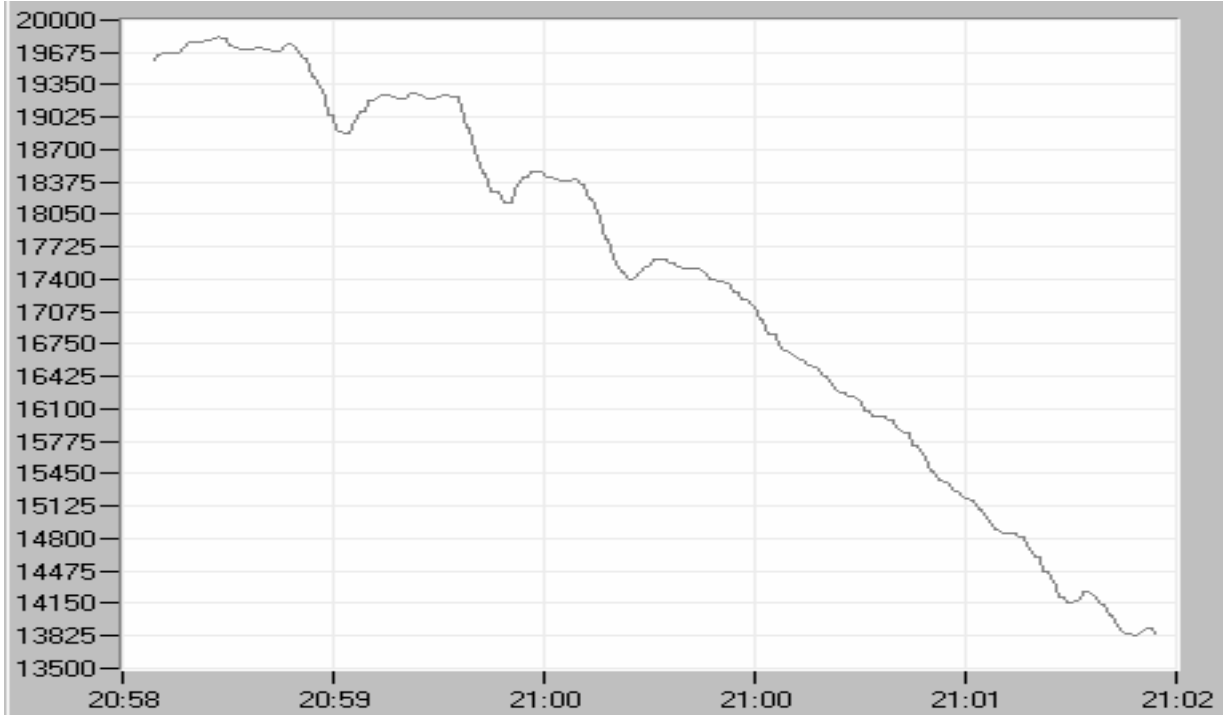

Time (min)

Figure 4.6 This is the continuation of Figure 4.5 showing from time 20.59. As the steady concentration of $20 \mathrm{mg} / \mathrm{m}^{3}$ was maintained for 4 min (needed for experiment) no dust is added through vibrator feeder and the concentration falls in the chamber as shown after time 21:00 


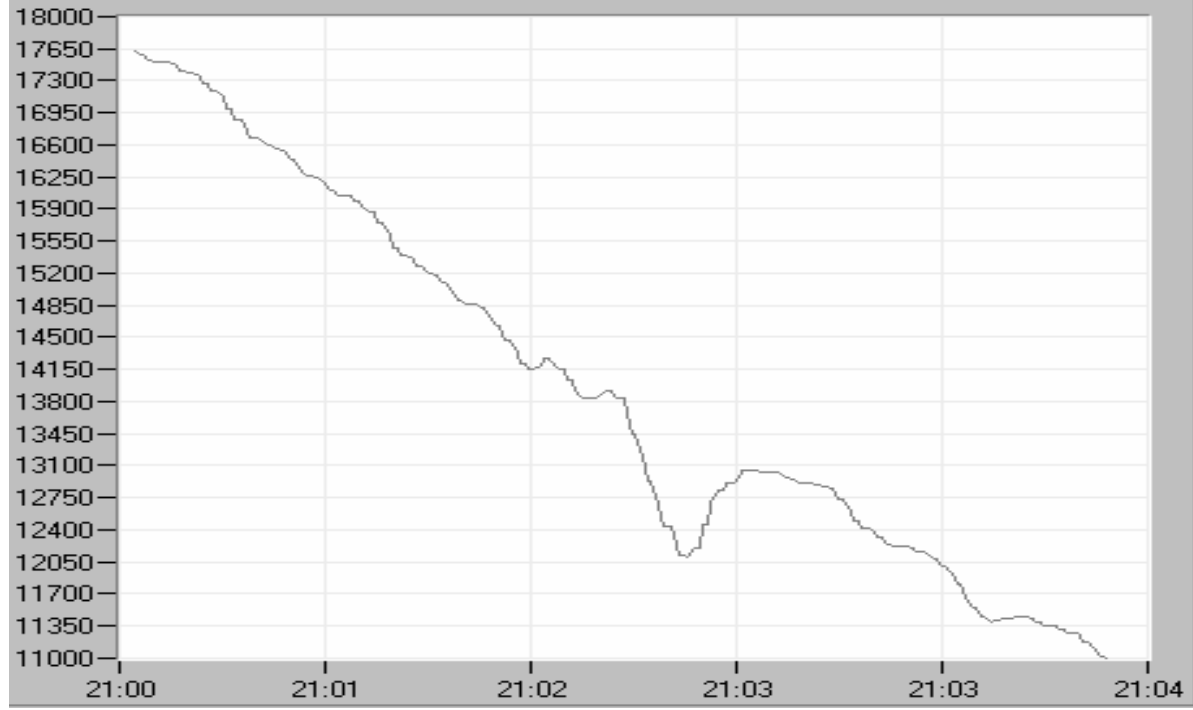

Time $(\min )$

Figure 4.7 This is the continuation of Figure 4.6 showing from time 21.01. This concentration in the chamber is fallen rapidly as no dust is added 


\section{2) 4 air changes per hour}

These figures show the graphical results of reaching the desired concentration of 20 $\mathrm{mg} / \mathrm{m}^{3}$ in the inhalation chamber at 4 air changes per hour and a relative humidity of 50 $\%$.

These graphs show the relation between dust concentration in $\mu \mathrm{g} / \mathrm{m}^{3}$ and time in hours and minutes with in the first 4 minutes of the experiment. This experiment was done at 4 air changes per hour of air flowing through each inhalation chamber. The experiment was started at time 20.36 where 20 represent the hours and 36 represent the minutes. The knob for controlling the feed rate on the vibrator feeder was kept at no.3. It took nearly 2 minutes to see some notable response to the concentration. When the knob is turned above no.3, it increases the feed rate which in turn increases the concentration in the chamber. This makes the response time to the dust less than 2 minutes. When the knob is turned below no. 3 , it decreases the feed rate and the response time would be greater than 2 minutes. This makes the slope of the concentration vs. response time curve to decrease.

For 4 air changes per hour, Figure 4.8 to Figure 4.12 represent in the same way as the plots in Figure 4.1 to Figure 4.7 above represent for 10 air changer per hour. 


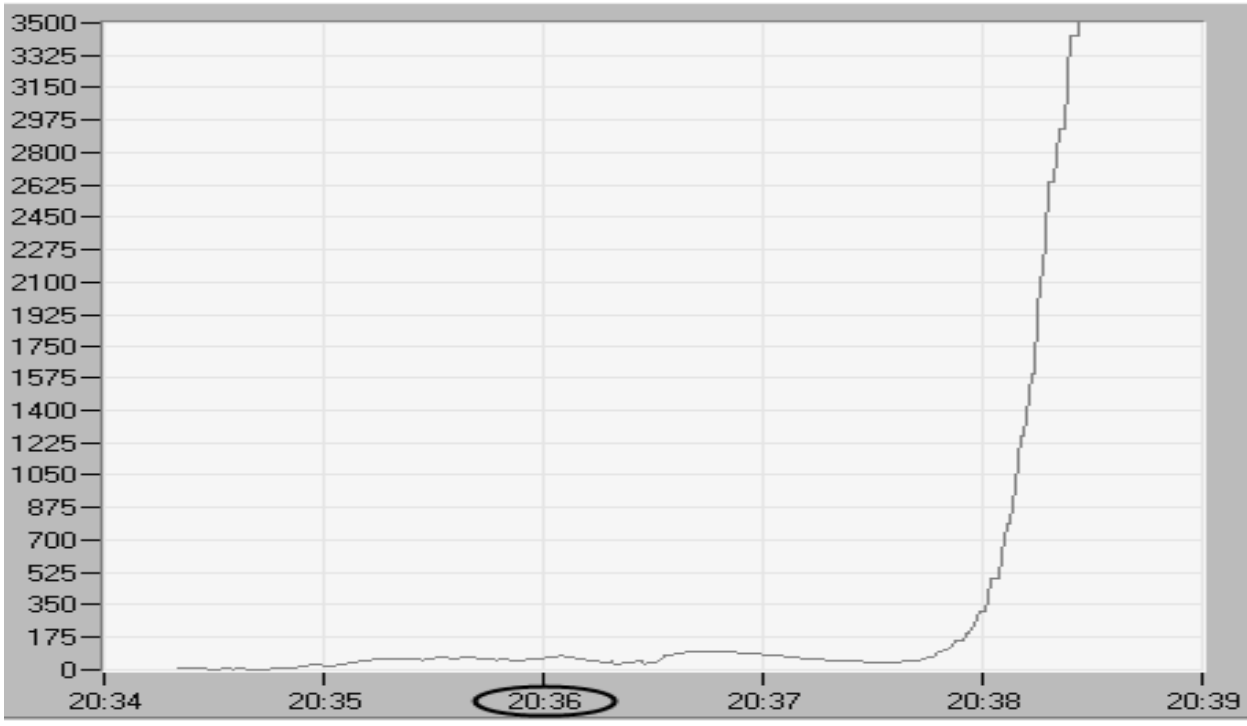

Time (min)

Figure 4.8 The experiment was started at time 20:36 where 20 represent the hours and 36 represent the minutes. The dust was added to chamber at 20:36. The change in the concentration by TEOM was recognized near $20: 38$

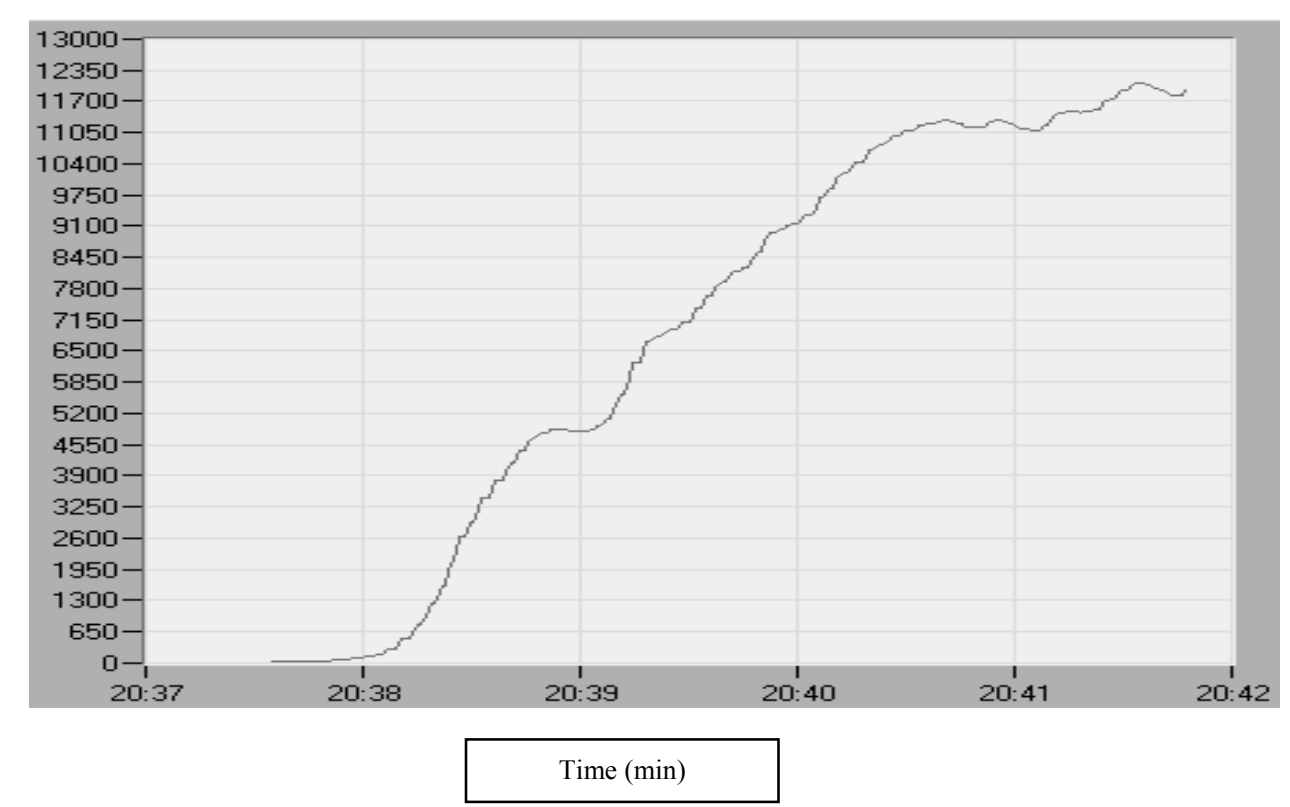

Figure 4.9 This is the continuation of Figure 4.8 showing from time

20.38. The vibrator feeder adds the dust continuously and jet mill pumps the dust into the chamber 


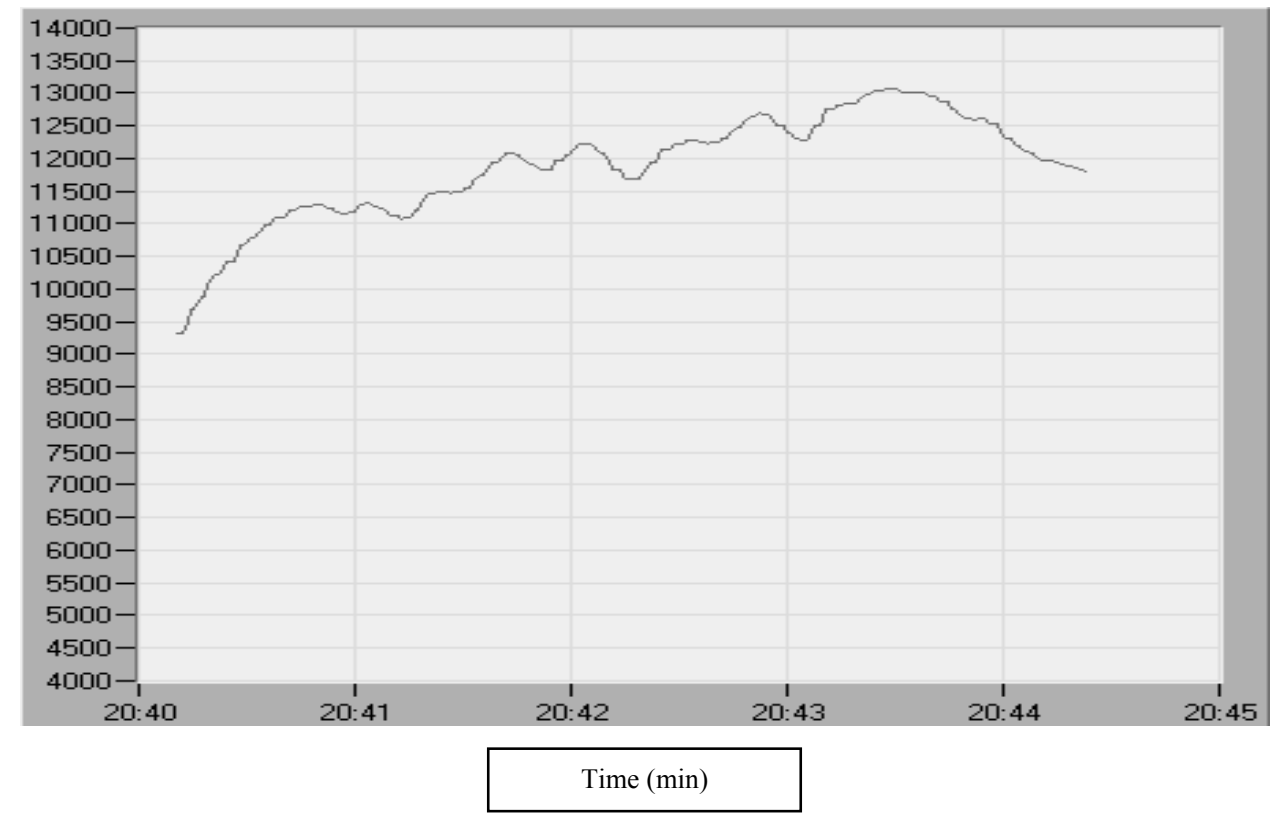

Figure 4.10 This is the continuation of Figure 4.9 showing from time 20.41. The vibrator feeder adds the dust continuously and jet mill pumps the dust into the chamber

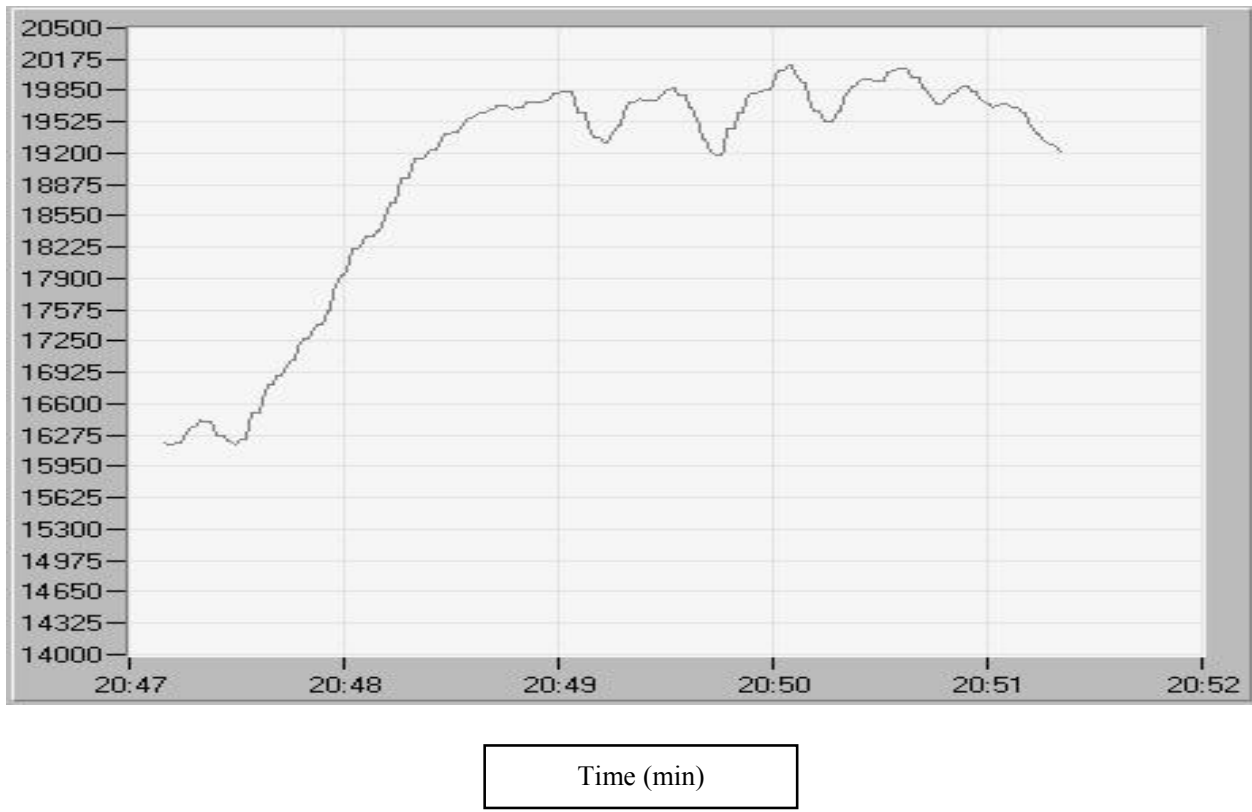

Figure 4.11 This is the continuation of Figure 4.10 showing from time 20.48. At this point it is close to $20 \mathrm{mg} / \mathrm{m}^{3}$ and starts to stay near that for some time. 


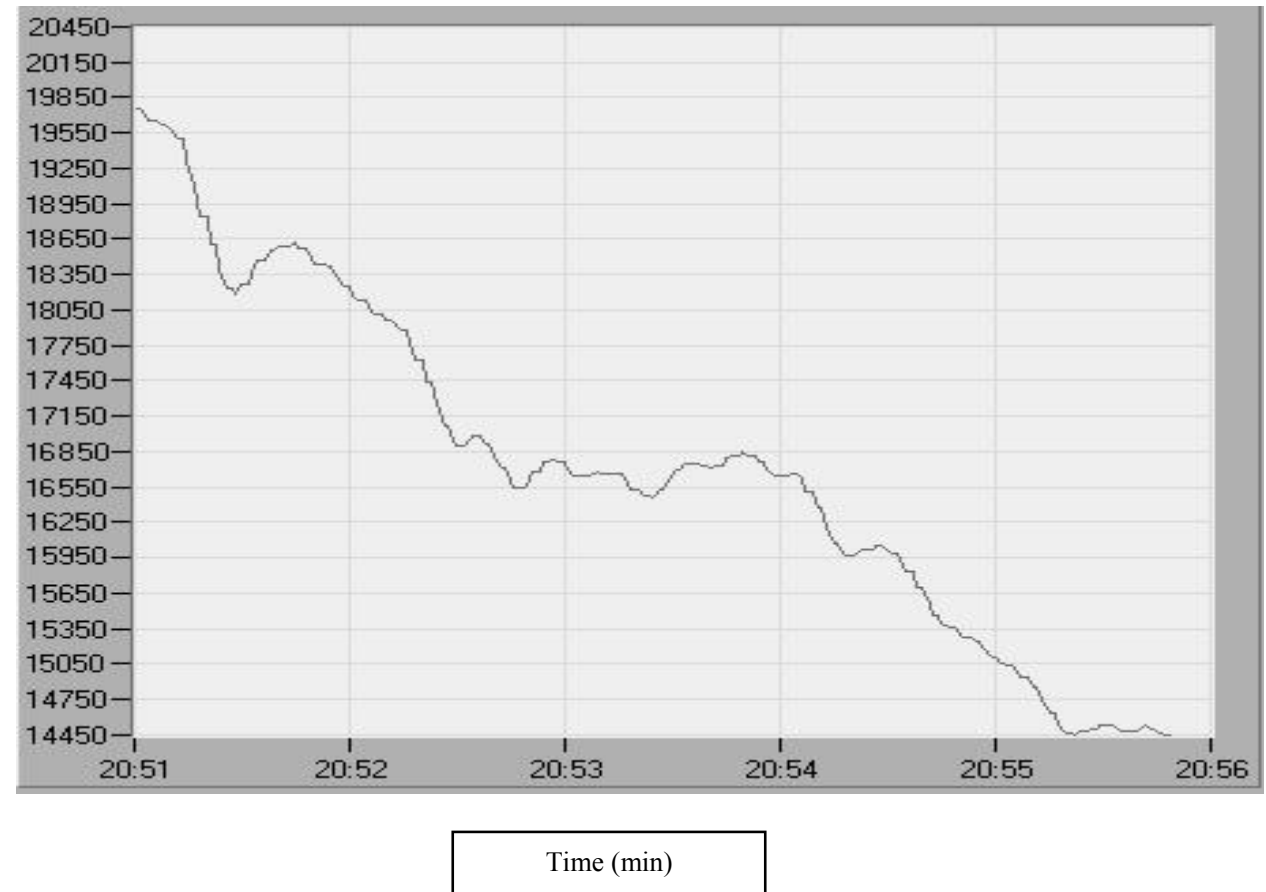

Figure 4.12 This is the continuation of Figure 4.11 showing from time 20.51. As no dust was added further after keeping the concentration close to $20 \mathrm{mg} / \mathrm{m}^{3}$ the concentration in the chamber falls rapidly. 


\section{THEORETICAL MODELING AND DISCUSSIONS}

\subsection{Introduction}

For determining the amount of DEP dust needed for any inhalation testing chamber, a theoretical model simulating the conditions of the testing procedure is needed. For the present testing chamber with $2.1 \mathrm{~m}^{3}$ of volume and with changing air cycles, a theoretical model has been derived. The results obtained from this model were compared to the result obtained from the experimental results.

\subsection{Problem report}

In this present case, the air inside the chamber is let out and fresh air is taken inside during the air cycles. The number of volumes of testing chamber that exits through the outlet from the chamber in an hour is considered as number of air changes. The aim is to calculate the DEP dust required to achieve the required concentration of DEP dust inside the testing chamber during the air changes and also to sustain that concentration over a period of time. The entire process of maintaining the $20 \mathrm{mg} / \mathrm{m}^{3}$ of concentration for four hours in the chamber, with inlet and outlet air flow, involves a transient state during which the concentration of the dust increase with time till it reaches required concentration and steady state during which the concentration is just maintained for a period of time. 


\subsection{Initial Condition and assumptions}

The main assumptions in this model are

i. There is no accumulation of powder in the chamber. That is powder does not settle at the bottom of the chamber

ii. The concentration inside the tank is same as concentration at the exit

\section{Transient State:}

Let us say during transient state, the powder supplied at a rate of $\mathrm{S}_{1}^{\prime}$.

The conservation equation for the dust is

[Dust in the chamber at time $\mathrm{t}+\Delta \mathrm{t}]-[$ Dust in the chamber at time $\mathrm{t}]=$

[Dust entered from the inlet during time $\Delta \mathrm{t}]-[$ Dust that left from exit during time $\Delta \mathrm{t}]+$

[Dust supplied through feeder during time $\Delta \mathrm{t}$ ]

The air entering through inlet is considered to be dust-free. The concentration of the DEP dust is zero for inlet air (only the feeder supplies the dust).

Dust entered from the inlet during time $\Delta \mathrm{t}=0 \times \Delta \mathrm{t}=0$

So,

$[\mathrm{XV}]_{(\mathrm{t}+\Delta \mathrm{t})}-[\mathrm{XV}]_{\mathrm{t}}=[0] \Delta \mathrm{t}-\left[\mathrm{X} \mathrm{v}^{\prime}\right] \Delta \mathrm{t}+\mathrm{S}_{1}^{\prime} \Delta \mathrm{t}$

From equation (1), dust entered from the inlet during time $\Delta \mathrm{t}$ is 0 .

Here $\mathrm{X}$ is the concentration of dust in $\mathrm{mg} / \mathrm{m}^{3}$ and

$\mathrm{V}$ is the volume of the chamber in $\mathrm{m}^{3}\left(2.1 \mathrm{~m}^{3}\right)$

From second assumption i.e. concentration inside the tank is same as concentration at the exit. 
Divide through out by $\Delta \mathrm{t}$

As $\Delta \mathrm{t} \rightarrow 0$

$\frac{[\mathrm{XV}]_{(\mathrm{t}+\Delta \mathrm{t})}-[\mathrm{XV}]_{(\mathrm{t})}}{\Delta \mathrm{t}}=-\left[\mathrm{X} \mathrm{v}^{\prime}\right]+\mathrm{S}_{1}^{\prime}$

$\frac{d(X V)}{d t}=-\left[X v^{\prime}\right]+S_{1}^{\prime}$

As the volume of the tank, $\mathrm{V}$ is constant

$$
\frac{d X}{d t}=-\frac{\mathrm{X} \mathrm{v}^{\prime}}{\mathrm{V}}+\frac{\mathrm{S}_{1}^{\prime}}{\mathrm{V}}
$$

This is a differential equation that governs the concentration as a function of time. We can solve it analytically when $\mathrm{v}^{\prime}$ and $\mathrm{S}_{1}$ are constants.

$$
\begin{aligned}
& \text { Say } \frac{\mathrm{v}^{\prime}}{\mathrm{V}}=\mathrm{a} \text { and } \frac{\mathrm{S}_{1}^{\prime}}{\mathrm{V}}=\mathrm{b} \\
& \frac{d(X)}{d t}=-\mathrm{aX}+\mathrm{b} \Rightarrow \frac{d(X)}{-\mathrm{aX}+\mathrm{b}}=\mathrm{dt}
\end{aligned}
$$


Integrating equation 7 ,

$-\frac{1}{a}[\ln (-\mathrm{aX}+\mathrm{b})]=\mathrm{t}+\ln \mathrm{C}$

Where $\mathrm{C}$ is a constant

$\ln (-a X+b)=-a t-a \ln c$

$-a X+b=C e^{-a t}$

Initial condition is that when $\mathrm{t}=0, \mathrm{x}=0$

$-a(0)+b=C e^{-a(0)}$

So, $\quad \mathrm{C}=\mathrm{b}$

Then final equation is

$-a X+b=b e^{-a t}$

$\Rightarrow \mathrm{X}=\frac{b}{a}\left[1-\mathrm{e}^{-\mathrm{at}}\right]$

$\Rightarrow \mathrm{X}=\frac{\mathrm{S}_{1}^{\prime}}{\mathrm{v}^{\prime}}\left[1-\mathrm{e}^{-\mathrm{at}}\right]$ 
Notice that as $\mathrm{t} \rightarrow \infty, \mathrm{X} \rightarrow \frac{\mathrm{S}_{1}^{\prime}}{\mathrm{v}^{\prime}}$ which is what we would expect.

Hence the formula in equation 10 is consistent.

\section{In case of 10 air changes per hour}

Now the problem is to find the $S_{1}^{\prime}$ such that $X$ becomes $20 \mathrm{mg} / \mathrm{m}^{3}$ at time $\mathrm{t}=13 \mathrm{~min}$ or $780 \mathrm{sec}$ (time taken to reach steady state)

$\mathrm{X}=\mathrm{S}_{1 \times}^{\prime} \times \frac{1-\mathrm{e}^{(5.833 \times 10-3 / 2.1) \times \mathrm{t}}}{5.833 \times 10^{-3}}$

For a concentration of $20 \mathrm{mg} / \mathrm{m}^{3}$ for 780 seconds it would be

$$
\begin{aligned}
\mathrm{X} & =20 \mathrm{mg} / \mathrm{m}^{3} \text { and } \\
\mathrm{t} & =780 \mathrm{sec}
\end{aligned}
$$

From equation 11, the rate of powder supplied is

$\mathrm{S}_{1}^{\prime}=0.132 \mathrm{mg} / \mathrm{sec}$

So dust added at a constant rate during first $13 \mathrm{~min}$ is $0.102 \mathrm{~g}$

\section{Steady State:}

Air change per hour $=10$

So, Volumetric flow rate, $\mathrm{v}^{\prime}=10 \times 2.1=21 \mathrm{~m}^{3} / \mathrm{hr}=5.833 \times 10^{-3} \mathrm{~m}^{3} / \mathrm{sec}$ 
Steady state concentration $=20 \mathrm{mg} / \mathrm{m}^{3}$

At steady state powder input rate = amount of powder coming out of the exit

Here the assumption is there is no accumulation of powder in the chamber. That is powder does not settle at the bottom of the chamber.

After reaching the required concentration the testing chamber has to be maintained the same concentration and in case of inlet and outlet flow of air excess amount of dust is required for maintaining the concentration and the formula is given in equation 3

Dust required under equilibrium $=($ Concentration required $) \times($ vol. flow rate $)$

In that case, powder input rate, $=20 \mathrm{mg} / \mathrm{m}^{3} \times 5.833 \times 10^{-3} \mathrm{~m}^{3} / \mathrm{sec}$

$$
\begin{aligned}
& =0.1167 \mathrm{mg} / \mathrm{sec} \\
& =420 \mathrm{mg} / \mathrm{hr}
\end{aligned}
$$

After Steady rate, $\mathrm{S}_{2}^{\prime}=420 \mathrm{mg} / \mathrm{hr}$

So dust needed for $4 \mathrm{~min}=28 \mathrm{mg}$

From the above analysis, Dust needed to reach the concentration $20 \mathrm{mg} / \mathrm{m}^{3}$ and maintain it for $4 \mathrm{hr}$ is the amount it needed for the transient state and for steady state. i.e.

$0.102+1.68=1.782 \mathrm{~g}$.

\section{In case of 4 air changes per hour}

Similarly calculating for 4 air changes per hour,

The amount of DEP dust required for transient state is : $0.064 \mathrm{~g}$

The amount of DEP required for steady state for $4 \mathrm{hrs}$ is: $0.672 \mathrm{~g}$

Hence the total amount required for the entire process it is: $0.736 \mathrm{~g}$ 


\subsection{Comparison between experimental results and theoretical method results}

Comparing between the results obtained theoretically and experimentally, there is approximately a $30 \%$ difference was observed. Theoretical results showed $\sim 30 \%$ lower values than the experimental values. Figures 5.1 and 5.2 show the theoretical and experimental values of the amount of DEP consumed for 10 and 4 air cycle changes per hour. The reasons for variation in experimental and theoretical values might be because of the following major reasons:

$>$ Due to the various losses during the process, the losses incurred in the pipe which is connected from the vibrating feeder to the chamber inlet,

Due to gravity the DEP dust might have settled at the bottom of the chamber after some time.

The efficiency of TEOM instrument in measuring the concentration of suspended particles inside the testing chamber. 


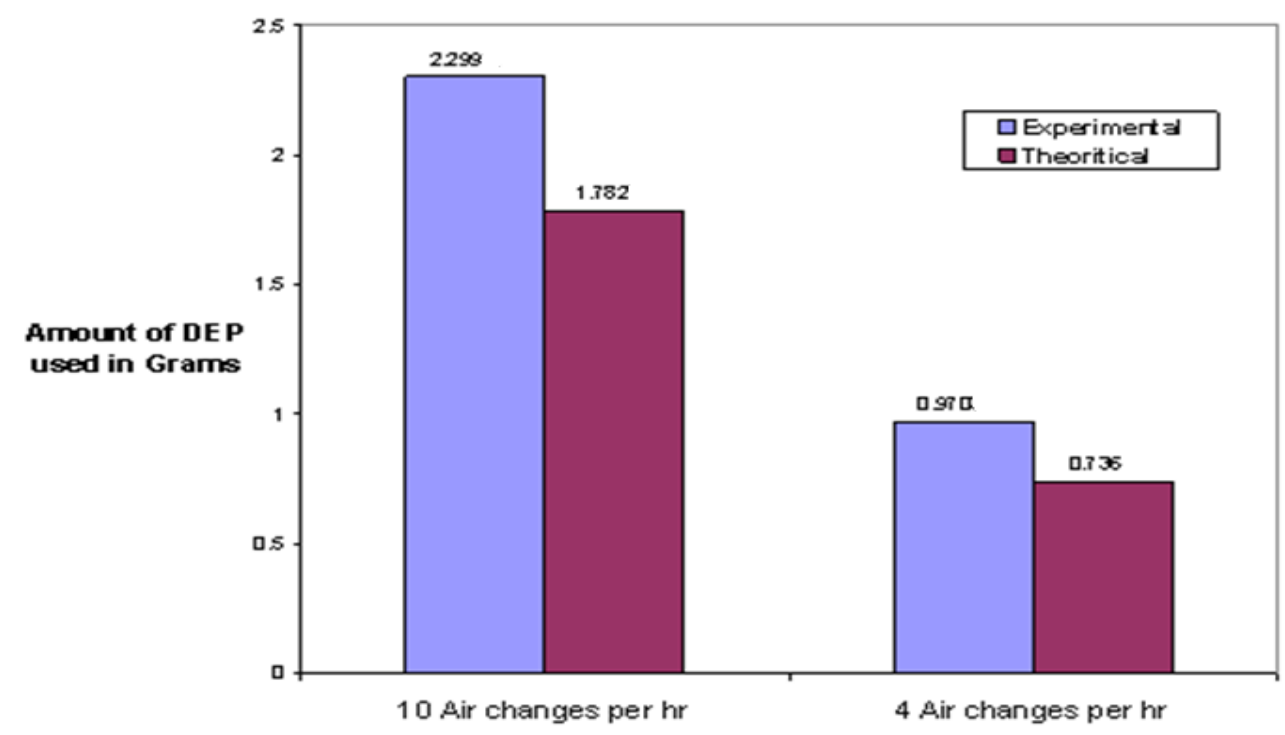

Figure 5.1 Theoretical and experimental values of the amount of DEP consumed for 10 and 4 air cycle changes per hour respectively

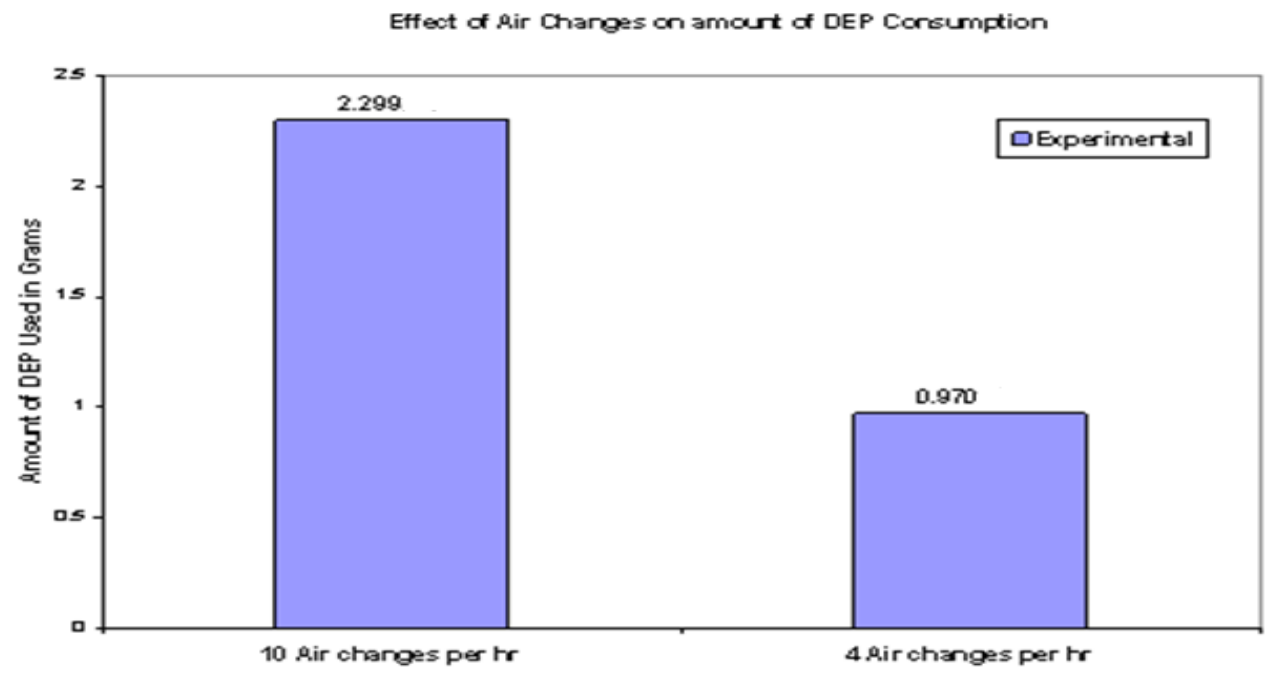

Figure 5.2 Chart showing the amount of DEP dust used for 10 and 4 air changes per hour during the experimentation 


\subsection{Effect of testing parameters on mass required for experimentation}

With respect to cost effectiveness of the entire experiment, one of the major challenges in conducting these experiments using DEP dust was to reduce the amount of DEP dust required during the experimentation. It can be achieved by choosing available optimum working conditions like feed rate and air cycle changes.

For foreseeing the DEP dust required and testing time for a given experimental set-up, a generalized graph showing the relation between the feed rates, time required for attaining steady state is needed. Moreover, this kind of generalized graph is also helpful in estimating the optimum testing parameters and for quick in situ verification of results of the experiments.

Using the governing equation derived in Section 5.3 for the present experiments, graphs representing the amount of DEP required and time for attaining steady state for given air cycle changes with varying feed rates was showed in Figure 5.3 (refer in Appendix B) 


\section{Varying Air Cycle changes Vs Time}

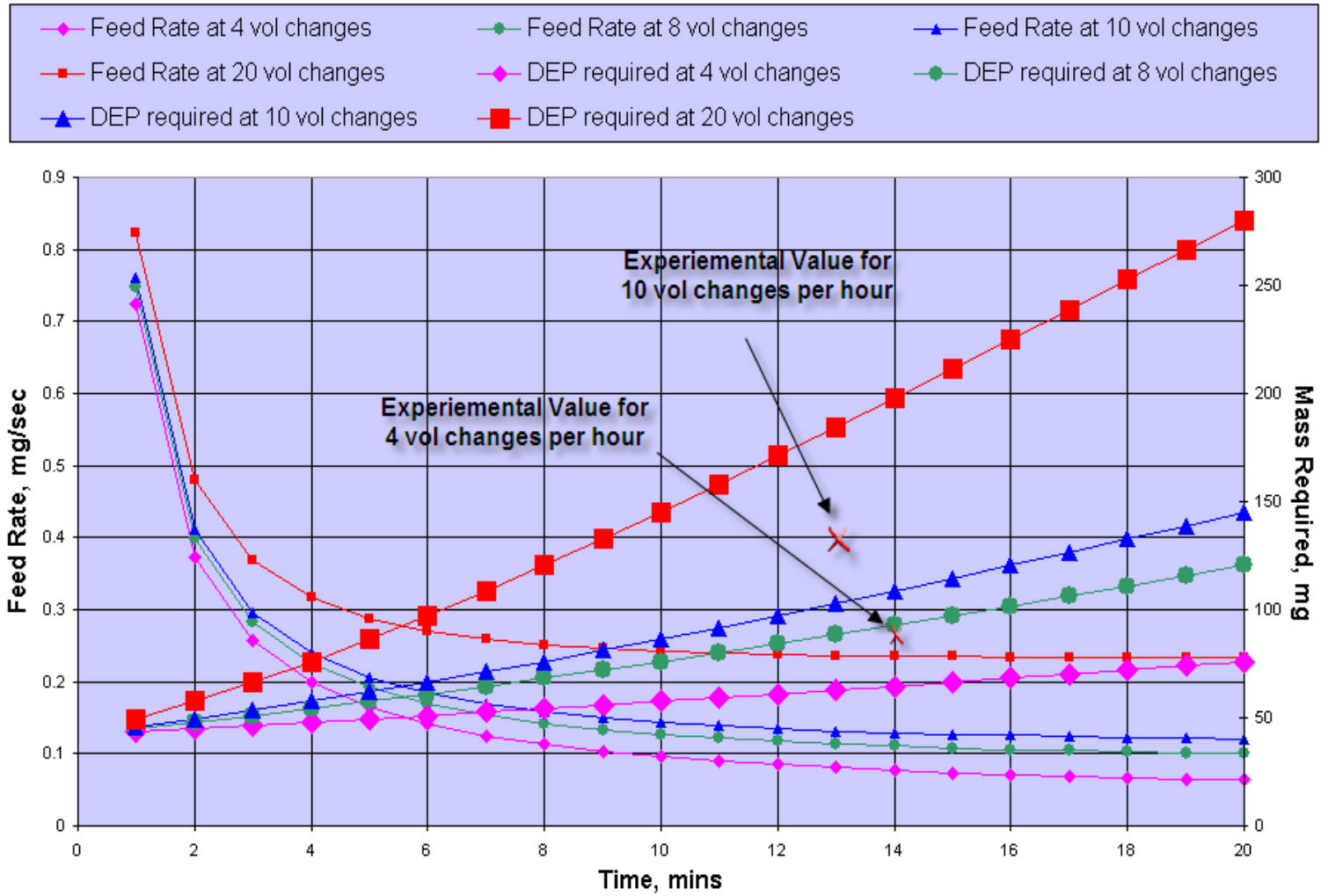

Figure 5.3 Graph representing amount of DEP and transient state time required for different air cycle changes with varying feed rates (Values in Appendix B)

To estimate the amount of DEP required for different volume changes and for given transient state time periods, a graphical representation was shown in Figure 5.3 (Values in Appendix B) and DEP required for different transient state time periods with varying volume changes was shown in figure 5.4(Values in Appendix C).

Figures 5.3 and 5.4 represent that with higher feed rate capability, the amount of DEP required for an experiment could be reduced to an optimum amount. 


\section{DEP Required for different steady state time periods with varying volumes changes per Hour}

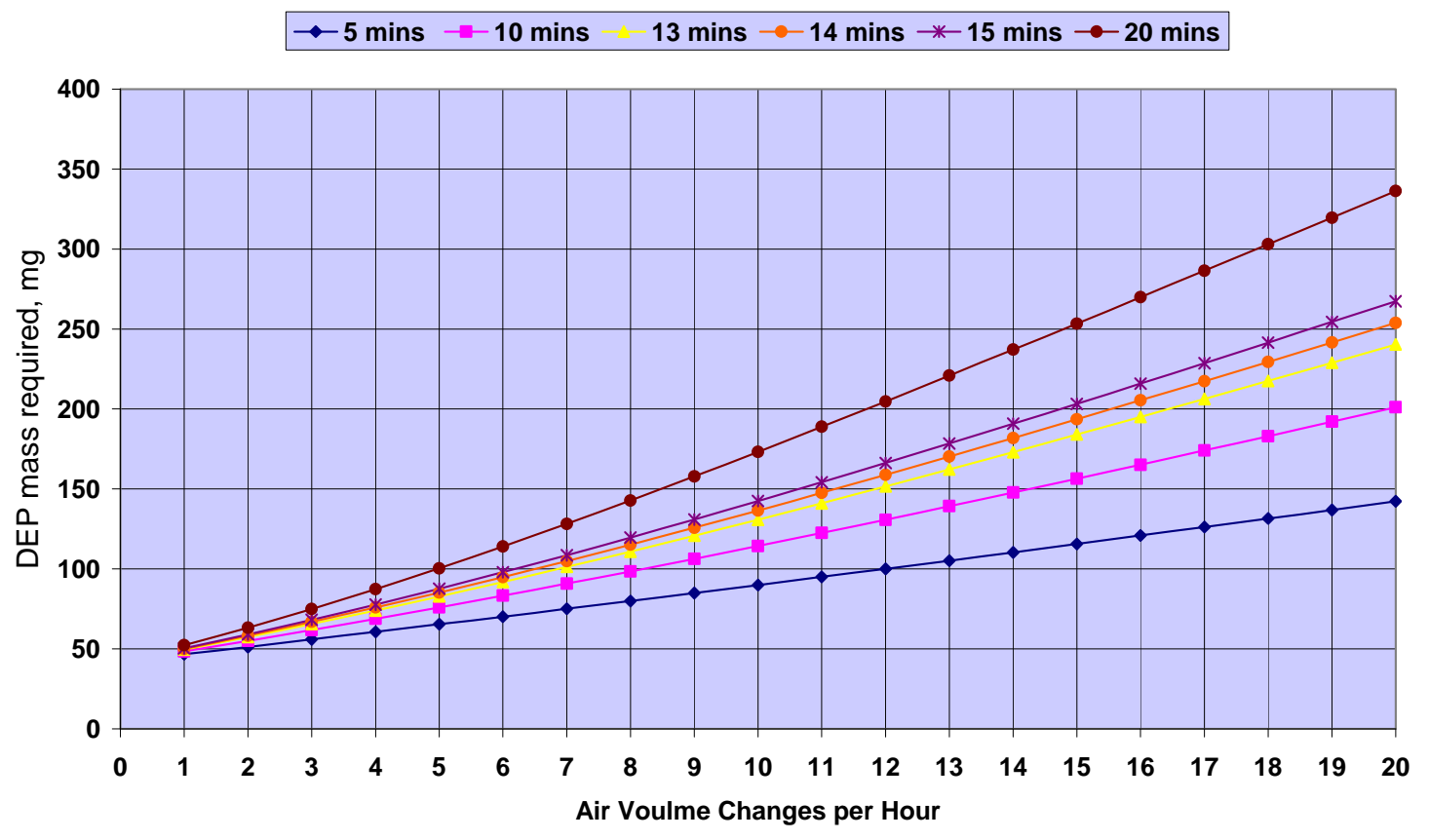

Figure 5.4 Graph representing DEP required for different transient state time periods with varying volume changes per hour (Values in Appendix C) 


\section{CONCLUSIONS}

\subsection{Introduction}

In this section conclusions are drawn from the methods used to monitor and control the testing environment of the inhalation testing chamber, experimental results obtained for measurement of DEP dust used for maintenance of required $20 \mathrm{mg} / \mathrm{m}^{3}$ of concentration in the air circulating testing chamber. Also, comparisons were made between results obtained from theoretical model and experimental method.

\subsection{Conclusions}

- Using Omega iTHX-5 temperature and humidity probe and i-server micro server, the alerts for change in humidity and temperature were successfully received. This enables the user to properly monitor the testing environment changes remotely.

* Using a voltage switch connected to an air humidifier inside the testing chamber, relative humidity inside the chamber was maintained at the desired level of $50 \%$ RH.

For maintaining $20 \mathrm{mg} / \mathrm{m}^{3}$ of concentration in the testing chamber of 10 air changes per hour for 4 hrs it took $2.29 \mathrm{~g}$ of DEP dust

For maintaining $20 \mathrm{mg} / \mathrm{m}^{3}$ of concentration in the testing chamber of 4 air changes per hour for 4 hrs it took $0.97 \mathrm{~g}$ of DEP dust

* Comparing the theoretical model results for 10 and 4 air changes per hour and the experimental results, it showed that the experimental values are $\sim 30 \%$ higher. 
Change in air changes per hour i.e. from 10 air changes to 4 air changes, in the testing chamber has significant effect on the amount of DEP dust $(\sim 1.04 \mathrm{~g})$

* A generalized graphical representation relating feed rate and mass of DEP dust required with respect to time and varying air changes in the testing chamber was demonstrated

- It was shown that the higher the feed rate into the testing chamber the lesser the requirement of DEP dust for experimentation

\subsection{Recommendations for future work}

$\checkmark$ A latest and sophisticated TEOM instrument is desired to avoid time lag (in the order of seconds) to maintain better response time

$\checkmark$ An air circulating device inside the testing chamber is recommended for avoiding the sedimentation of testing powder in the chamber during feeding

$\checkmark$ A controlled, automated and high powered feeding machine is needed for enabling faster feeding rate 


\section{REFERENCES}

1) Suppression of Cell-Mediated Immune Responses to Listeria Infection by Repeated Exposure to Diesel Exhaust Particles in Brown Norway Rats. Xuejun J. Yin, Caroline C. Dong, Jane Y. C. Ma, James M. Antonini, Jenny R. Roberts, Charles F. Stanley, Rosana Schafer and Joseph K. H. Ma. 2003.

2) Hui-Min Yang, James M. Antonini, Mark W. Barger,Leon Butterworth, Jenny R. Roberts, Joseph K.H. Ma, Vince Castranova, and Jane Y.C. Ma. Diesel Exhaust Particles Suppress Macrophage Function and Slow the Pulmonary Clearance of Listeria Monocytogenes in Rats, Environmental Health Perspectives Volume 109, Number 5, 2001

3) Donaldson K, Li XY, MacNee W. Ultrafine (nanometer) particle mediated lung injury. J Aerosol Sci. 1998;29:553-560.

4) Oberdorster G. Significance of particle parameters in the evaluation of exposuredose relationships of inhaled particles. Inhal Toxicol. 1996;8(suppl):73-90.

5) Oberdorster G, Ferin J, Gelein R, Soderholm SC, Finkelstein J. Role of the alveolar macrophage in lung injury: studies with ultrafine particles. Environ Health Perspect. 1992;97:193-199. 
6) Oberdorster G, Utell MK. Ultrafine particles in the urban air: to the respiratory tract—and beyond? Environ Health Perspect. 2002;110:A440-A441.

7) Lee KP, Trochimowicz HJ, Reinhardt CF. Pulmonary response of rats exposed to titanium dioxide (TiO2) by inhalation for two years. Toxicol Appl Pharmacol. 1985 Jun 30;79(2):179-192.

8) Lee KP, Henry NW 3rd, Trochimowicz HJ, Reinhardt CF. Pulmonary response to impaired lung clearance in rats following excessive $\mathrm{TiO} 2$ dust deposition. Environ Res. 1986 Oct;41(1):144-167.

9) Ferin J, Oberdorster G, Penney DP. Pulmonary retention of ultrafine and fine particles in rats. Am J Respir Cell Mol Biol. 1992;6:535-542

10) Heinrich U, Muhle H, Takenaka S, Ernst H, Fuhst R, Mohr U, Pott F, Stöber W. Chronic effects on the respiratory tract of hamsters, mice and rats after long-term inhalation of high concentrations of filtered and unfiltered diesel engine emissions. J Appl Toxicol. 1986 Dec;6(6):383-395.

11) Peters A, Wichmann HE, Tuch J, Heinrich J, Heyder J. Respiratory effects are associated with the number of ultra-fine particles. Am J Respir Crit Care Med. 1997;155(4):1376-1383. 
12) Dasenbrock C, Peters L, Creutzenberg O, Heinrich U: The carcinogenic potency of carbon particles with and without PAH after repeated intratracheal administration in the rat. Toxicology Letters 1996, 88:15-21.

13) Driscoll KE, Costa DL, Hatch G, Henderson R, Oberdorster G, Salem H, Schlesinger RB. Intratracheal instillation as an exposure technique for the evaluation of respiratory tract toxicity: uses and limitations. Toxicol Sci 2000;55:24-35

14) K J Nikula, K J Avila, W C Griffith, and J L Mauderly. Sites of particle retention and lung tissue responses to chronically inhaled diesel exhaust and coal dust in rats and cynomolgus monkeys. Environ Health Perspect. 1997 September; 105(Suppl 5): 12311234

15) Paul M. Hext, John A. Tomenson, and Peter Thompson. Titanium Dioxide: Inhalation Toxicology and Epidemiology. Annals of Occupational Hygiene 2005 49(6):461-472

16) Snipes MB. Current information on lung overload in nonrodent mammals: contrast with rats. Inhal Toxicol 8(suppl 1):91-109 (1996).

17) Nikula KJ, Snipes MB, Barr EB, Griffith WC, Henderson RF, Mauderly JL. Comparative pulmonary toxicities and carcinogenicities of chronically inhaled diesel exhaust and carbon black in F344 rats. Fundam Appl Toxicol 25:80-94 (1995). 
18) Warheit, D. B., Brock, W. J., Lee, K. P., Webb, T. R., and Reed, K. L. (2005). Comparative pulmonary toxicity inhalation and instillation studies with different $\mathrm{TiO} 2$ particle formulations: Impact of surface treatments on particle toxicity. Toxicol. Sci. 88, 514-524.

19) Donaldson, K., Gilmour, P. S., MacNee, W., and Oberdorster, G. (1995). Free radical activity associated with ultrafine titanium dioxide particles and PM10 material. Am. J. Respir. Crit. Care Med. 151, A64.

20) Seaton (1995) "Particulate Air Pollution and Acute Health Effects". The Lancet, 345: $176-178$

21) Bair WJ, Thompson RC. Plutonium: biomedical research. Science. 1974 Feb $22 ; 183(126): 715-722$

22) Stone, V., J. Shaw, D. M. Brown, W. MacNee, S. P. Faux, and K. Donaldson. 1998. The role of oxidative stress in the prolonged inhibitory effect of ultrafine carbon black on epithelial cell function. Toxicol. In Vitro 12: 649-659

23) Behrendt H \& Becker W (2001). Localization release and bioavailability of pollen allergens: the Influence of Environmental Factors. Curr Opin Immunol 13: 709-715. 
24) H. J. Moller, N. A. Peterslund, J. H. Graversen, and S. K. Moestrup. Identification of the hemoglobin scavenger receptor/CD163 as a natural soluble protein in plasma. Blood, January 1, 2002; 99(1): $378-380$

25) Nemmar A, Hoet PH, Vanquickenborne B, Dinsdale D, Thomeer M, Hoylaerts MF, et al. Passage of inhaled particles into the blood circulation in humans. Circulation. $2002 ; 105: 411-414$

26) Elder ACP, Gelein R, Azadniv M, Frampton M, Finkelstein J, Oberdorster G. 2002. Systemic interactions between inhaled ultrafine particles and endotoxin. Ann Occup Hyg 46(suppl 1):231-234.

27) Kreyling WG, Semmler M, Möller W. In press. Ultrafine particle-lung interactions: does size matter? J Aerosol Med.

28) Donaldson K, Stone V, Clouter A, Renwick L, MacNee W (2001) Ultrafine particles. Occup Environ Med 58:211-216

29) Kapp N, Kreyling W, Im Hof V, Schulz H, Gehr P, Geiser M. Electron energy loss spectroscopy for analysis of inhaled ultrafine particles in rat lungs. Microsc Res Tech. 2004;63:298-305. 
30) Stone, P.H., Godleski J.J. First steps toward understanding the pathophysiologic link between air pollution and cardiac mortality. Am Heart J. 138: 804-807, 1999.

31) Stearns, R. C., M. Katler, and J. J. Godleski. 1994. Contribution of osmium tetroxide to the image quality and detectability of iron in cells studied by electron spectroscopic imaging and electron energy loss spectroscopy. Microsc. Res. Tech. 28: $155-163$

32) Johnston CJ, Finkelstein JN, Mercer P, Corson N, Gelein R, Oberdorster G. 2000. Pulmonary effects induced by ultrafine PTFE particles. Toxicol Appl Pharmacol 168: 208-215. 


\section{APPENDIX A}

\section{COMPOSITION OF NIST-SRM 2975}

\section{From: The IAEA Database of Natural Matrix Reference Material}

Website: http://www-naweb.iaea.org/nahu/nmrm/nmrm2003/material/ni2975.htm)

\begin{tabular}{|c|c|c|c|}
\hline Unit size: & $1 \mathrm{~g}$ & Producer: & NIST \\
\hline Min. Wt.: & $100 \mathrm{mg}$ & Certifying Body: & Standard Reference Materials Program \\
\hline Unit Price: & $\$ 196$ & & \\
\hline
\end{tabular}

Values are quoted as $\mathrm{mg} / \mathrm{kg}$ unless noted in column "Remarks".

\begin{tabular}{|c|c|c|c|c|}
\hline MEASURAND & $\begin{array}{l}\text { Value } \\
\text { type }\end{array}$ & Value & $\begin{array}{l}\text { Assc. Unc } \\
\text { (\%) }\end{array}$ & Remarks \\
\hline Banz[a]anthracene & $\mathrm{C}$ & 0.317 & 21 & \\
\hline Benzo[a]pyrene & C & 0.0522 & 10 & \\
\hline Benzo[e]pyrene & C & 1.11 & 9 & \\
\hline Benzo[ghi]perylene & C & 0.498 & 9 & \\
\hline Benzo[j]fluoranthene & C & 0.82 & 13 & \\
\hline Benzo[k]fluoranthene & C & 0.678 & 11 & \\
\hline Chrysene & $\mathrm{C}$ & 4.56 & 4 & \\
\hline Fluoranthene & C & 26.6 & 19 & \\
\hline Phenanthrene & $\mathrm{C}$ & 17 & 16 & \\
\hline Pyrene & $\mathrm{C}$ & 0.9 & 27 & \\
\hline Triphenylene & C & 5.22 & 4 & \\
\hline Anthracene & $\mathrm{N}$ & 0.038 & 21 & \\
\hline Benzo[a]fluroanthene & $\mathrm{N}$ & 0.06 & 3 & \\
\hline Benzo[b]chrysene & $\mathrm{N}$ & 0.08 & 38 & \\
\hline Benzo[b]fluroanthene & $\mathrm{N}$ & 11.5 & 31 & \\
\hline Benzo[c]phenanthrene & $\mathrm{N}$ & 1 & 40 & \\
\hline Benzo[ghi]fluoranthene & $\mathrm{N}$ & 10.2 & 5 & \\
\hline Coronene & $\mathrm{N}$ & 1.1 & 18 & \\
\hline $\begin{array}{l}\text { Dibenzo[a,c]anthracene / } \\
\text { Dibenzo[a,h]anthracene }\end{array}$ & $\mathrm{N}$ & 0.52 & 15 & \\
\hline Dibenzo[a,j]anthracnene & $\mathrm{N}$ & 0.37 & 19 & \\
\hline Fluoranthene, 8-methyl- & $\mathrm{N}$ & 0.068 & 6 & \\
\hline
\end{tabular}




\begin{tabular}{|l|c|c|c|c|}
\hline Fluroanthene, 1-, 3- and 7-methyl- & $\mathrm{N}$ & 0.53 & 1 & \\
\hline Indeno[1,2,3-cd]fluoranthene & $\mathrm{N}$ & 1.1 & 18 & \\
\hline Indeno[1,2,3-cd]pyrene & $\mathrm{N}$ & 1.4 & 14 & \\
\hline Pentaphene & $\mathrm{N}$ & 0.038 & 18 & \\
\hline Perylene & $\mathrm{N}$ & 0.054 & 17 & \\
\hline Phenanthrene, 1,2-dimethyl- & $\mathrm{N}$ & 0.05 & 40 & \\
\hline $\begin{array}{l}\text { Phenanthrene, 1,6-, 2,5- and 2,9- } \\
\text { dimethyl- }\end{array}$ & $\mathrm{N}$ & 0.57 & 14 & \\
\hline Phenanthrene, 1,8-dimethyl- & $\mathrm{N}$ & 0.06 & 33 & \\
\hline Phenanthrene, 1-methyl- & $\mathrm{N}$ & 0.89 & 12 & \\
\hline Phenanthrene, 2,6-dimethyl- & $\mathrm{N}$ & 0.25 & 20 & \\
\hline Phenanthrene, 2,7-dimethyl- & $\mathrm{N}$ & 0.23 & 22 & \\
\hline Phenanthrene, 2-methyl- & $\mathrm{N}$ & 2 & 10 & \\
\hline Phenanthrene, 3- and 4-methyl- & $\mathrm{N}$ & 0.44 & 20 & \\
\hline Phenanthrene, 3,6-dimethyl- & $\mathrm{N}$ & 0.18 & 11 & \\
\hline Phenanthrene, 3-methyl- & $\mathrm{N}$ & 1 & 20 & \\
\hline Picene & $\mathrm{N}$ & 1 & 20 & \\
\hline Pyrene, 1-nitro- & $\mathrm{N}$ & 36 & & \\
\hline Pyrene, 2-methyl- & $\mathrm{N}$ & 0.04 & 20 & \\
\hline Pyrene, 4-methyl- & 0.022 & 23 & \\
\hline
\end{tabular}

*A variety of terms is also currently used to describe the concentration values reported, e.g. "certified", "recommended", "assigned", "indicated", "non-certified", and "information". The compilers of the database have adapted the terminology in such a way that only two types of values are recognized here, either certified [C] or information [I] ones or non-certified [N]

**Information included in the database is on values for measurands determined in reference materials, producers, the cost, and the unit size supplied. The recommended minimum weight of material for analysis is also recorded, if available. 
The relevant information has been extracted from certificates of analysis, information sheets, and other reports provided by the reference material producers. As a general rule, the compilers have only included reference materials for which a certificate of analysis is on file or for which there was information provided electronically by the producers. However, this was not available from all the producers. In such cases the information was taken from the producer's catalogue and, after entry into the database, the tables containing the data were sent to the producer for approval.

*** The unit of all values is $\mathrm{mg} / \mathrm{kg}$ unless otherwise mentioned in the "Remarks" field of the database. Uncertainties are recorded as percentage of the measurand value, derived from the uncertainties, confidence intervals, etc. that are provided in the certificates. In most instances the assigned uncertainty is close to the $95 \%$ confidence interval. Uncertainties are entered only for certified values. 


\section{APPENDIX B}

\begin{tabular}{|c|c|c|c|c|c|c|c|c|}
\hline \multirow{2}{*}{$\begin{array}{c}\text { Steady } \\
\text { State } \\
\text { Time }\end{array}$} & \multicolumn{2}{|c|}{$\begin{array}{c}4 \text { vol changes per } \\
\mathrm{hr}\end{array}$} & \multicolumn{2}{|c|}{$\begin{array}{c}8 \text { vol changes per } \\
\mathrm{hr}\end{array}$} & \multicolumn{2}{|c|}{$\begin{array}{c}10 \text { vol changes per } \\
\mathrm{hr}\end{array}$} & \multicolumn{2}{|c|}{$\begin{array}{c}20 \text { vol changes per } \\
\mathrm{hr}\end{array}$} \\
\hline & 0.724 & 43.416 & 0.748 & 44.862 & 0.760 & 45.597 & 0.823 & 49.388 \\
\hline 2 & 0.374 & 44.862 & 0.399 & 47.849 & 0.412 & 49.388 & 0.480 & 57.544 \\
\hline 3 & 0.257 & 46.340 & 0.283 & 50.959 & 0.297 & 53.371 & 0.369 & 66.443 \\
\hline 4 & 0.199 & 47.849 & 0.226 & 54.191 & 0.240 & 57.543 & 0.317 & 76.045 \\
\hline 5 & 0.165 & 49.388 & 0.192 & 57.544 & 0.206 & 61.902 & 0.288 & 86.300 \\
\hline 6 & 0.142 & 50.959 & 0.169 & 61.016 & 0.185 & 66.441 & 0.270 & 97.147 \\
\hline 7 & 0.125 & 52.559 & 0.154 & 64.606 & 0.169 & 71.157 & 0.258 & 108.524 \\
\hline 8 & 0.113 & 54.191 & 0.142 & 68.309 & 0.158 & 76.043 & 0.251 & 120.363 \\
\hline 9 & 0.103 & 55.853 & 0.134 & 72.123 & 0.150 & 81.092 & 0.246 & 132.602 \\
\hline 10 & 0.096 & 57.544 & 0.127 & 76.045 & 0.144 & 86.297 & 0.242 & 145.179 \\
\hline 11 & 0.090 & 59.266 & 0.121 & 80.072 & 0.139 & 91.650 & 0.239 & 158.040 \\
\hline 12 & 0.085 & 61.016 & 0.117 & 84.200 & 0.135 & 97.144 & 0.238 & 171.134 \\
\hline 13 & 0.081 & 62.797 & 0.113 & 88.424 & 0.132 & 102.769 & 0.236 & 184.420 \\
\hline 14 & 0.077 & 64.606 & 0.110 & 92.741 & 0.129 & 108.519 & 0.236 & 197.861 \\
\hline 15 & 0.074 & 66.443 & 0.108 & 97.147 & 0.127 & 114.385 & 0.235 & 211.425 \\
\hline 16 & 0.071 & 68.309 & 0.106 & 101.638 & 0.125 & 120.358 & 0.234 & 225.087 \\
\hline 17 & 0.069 & 70.202 & 0.104 & 106.209 & 0.124 & 126.431 & 0.234 & 238.826 \\
\hline 18 & 0.067 & 72.123 & 0.103 & 110.857 & 0.123 & 132.595 & 0.234 & 252.626 \\
\hline 19 & 0.065 & 74.071 & 0.101 & 115.576 & 0.122 & 138.845 & 0.234 & 266.473 \\
\hline 20 & 0.063 & 76.045 & 0.100 & 120.363 & 0.121 & 145.172 & 0.234 & 280.357 \\
\hline
\end{tabular}




\section{APPENDIX C}

\begin{tabular}{|c|c|c|c|c|c|c|}
\hline \multirow{2}{*}{$\begin{array}{l}\text { Volume } \\
\text { Changes } \\
\text { per Hour }\end{array}$} & \multicolumn{6}{|c|}{ Steady State time, min } \\
\hline & $5 \mathrm{~min}$ & $10 \mathrm{~min}$ & $13 \mathrm{~min}$ & $14 \mathrm{~min}$ & $15 \mathrm{~min}$ & $20 \mathrm{~min}$ \\
\hline 1 & 46.574 & 48.397 & 49.514 & 49.890 & 50.269 & 52.188 \\
\hline 2 & 51.197 & 54.988 & 57.355 & 58.159 & 58.971 & 63.144 \\
\hline 3 & 55.869 & 61.771 & 65.518 & 66.801 & 68.101 & 74.843 \\
\hline 4 & 60.588 & 68.744 & 73.997 & 75.806 & 77.643 & 87.245 \\
\hline 5 & 65.356 & 75.903 & 82.779 & 85.159 & 87.581 & 100.300 \\
\hline 6 & 70.171 & 83.243 & 91.855 & 94.846 & 97.895 & 113.947 \\
\hline 7 & 75.034 & 90.759 & 101.208 & 104.847 & 108.559 & 128.124 \\
\hline 8 & 79.944 & 98.445 & 110.824 & 115.141 & 119.547 & 142.763 \\
\hline 9 & 84.901 & 106.295 & 120.685 & 125.708 & 130.834 & 157.802 \\
\hline 10 & 89.903 & 114.300 & 130.774 & 136.524 & 142.390 & 173.179 \\
\hline 11 & 94.951 & 122.454 & 141.072 & 147.567 & 154.188 & 188.840 \\
\hline 12 & 100.043 & 130.747 & 151.561 & 158.814 & 166.202 & 204.734 \\
\hline 13 & 105.179 & 139.174 & 162.225 & 170.245 & 178.406 & 220.820 \\
\hline 14 & 110.359 & 147.724 & 173.045 & 181.839 & 190.777 & 237.061 \\
\hline 15 & 115.581 & 156.390 & 184.006 & 193.577 & 203.293 & 253.425 \\
\hline 16 & 120.845 & 165.163 & 195.092 & 205.441 & 215.934 & 269.887 \\
\hline 17 & 126.150 & 174.037 & 206.289 & 217.416 & 228.683 & 286.426 \\
\hline 18 & 131.495 & 183.002 & 217.584 & 229.485 & 241.523 & 303.026 \\
\hline 19 & 136.878 & 192.052 & 228.965 & 241.638 & 254.441 & 319.673 \\
\hline 20 & 142.300 & 201.179 & 240.420 & 253.861 & 267.425 & 336.357 \\
\hline
\end{tabular}

